\title{
Pre-trade Transparency in Over-the-Counter Markets
}

\author{
Fan Chen \\ Division of Finance, Michael F. Price College of Business, University of Oklahoma, 205-A Adams Hall, \\ Norman, Oklahoma 73019, fanchen@ou.edu \\ Zhuo Zhong \\ Department of Economics, Cornell University, Uris Hall, Ithaca, NY 14853, zz225@cornell.edu \\ This version: August, 2012
}

\begin{abstract}
To understand whether and how pre-trade transparency would affect over-the-counter markets, we construct a search model and test our model implications in corporate bond markets. Based on our search model, we argue that the increase in pre-trade information, which refines traders' information sets, enhances traders' bargaining positions relative to dealers'. Thus, traders' transaction costs measured by bid-ask spreads are reduced. Smaller bid-ask spreads induce more traders to participate, and hence, lead to an increase in market liquidity. Our model is novel in that we consider traders' lack of pre-trade information as Knightian uncertainty. In other words, the unavailability of pre-trade information impedes the formation of a unique prior for traders. Our model implications are supported through a controlled experiment on the corporate bond market. Using propensity score matching to construct groups of bonds with and without pre-trade information, we find that the average effective bid-ask spread is 11 basis points lower on pretrade transparent bonds. This means that a minimum of $\$ 930$ million would be saved annually on transaction costs if pre-trade transparency had been enforced.
\end{abstract}




\section{Introduction}

Transparency is always an important element pertaining to market design. While many have explored the importance and the consequence of bringing post-trade transparency to overthe-counter (OTC, henceforth) markets, almost no research has been done to understand how pre-trade transparency affects OTC trading. Post-trade transparency can be defined as the availability of information following a transaction such as prices and volumes, while pre-trade transparency is the availability of information prior to a transaction such as trade interest and quotations. OTC markets have suffered intense criticism due to their lack of transparency and failure to provide continuous order flow during the 2008 financial crisis. In the crisis, the opaqueness of OTC markets made price discovery and liquidity very challenging, and investors were deterred from trading. If pre-trade transparency were enforced, the situation might be different. Pre-trade transparency, which provides real-time access to pre-trade pricing information, helps public investors evaluate their assets, and hence, make better trade decisions and improve risk management. There is a clear benefit and need for greater pre-trade transparency in OTC markets. In addition, both regulators and practitioners view pre-trade transparency as equally important to post-trade transparency in OTC trading. In his keynote address in October 2010 at the National Association of Bond Lawyers 35th Bond Attorneys' Workshop, Elisse Walter, Commissioner of Securities and Exchange, said, "Again, that is why I believe that improved pre-trade transparency is an important goal. Investors need better information and better access both to tap and provide liquidity in the market."

Despite unanimous agreement on the importance of pre-trade transparency, practitioners disagree on the effect it can generate. In June 2010, a survey report from the International Capital Market Association found the majority of corporate bond market participants believed that pretrade transparency was the most important measure to improve market liquidity. ${ }^{1}$ Whereas, in March 2010, another survey report from the Association for Financial Markets in Europe showed a third of traders believed greater pre-trade transparency would negatively impact liquidity. ${ }^{2}$ This

\footnotetext{
${ }^{1}$ In the International Capital Market Association's report, $83 \%$ of survey respondents ranked pre-trade transparency as the most important measure to improve liquidity, compared with $57 \%$ who believed improvements in liquidity are best accomplished through post-trade transparency. Source: http://www.icmagroup.org/assets/documents/MaketPractice/Regulatory-Policy/MiFID-

BMT/ICMA\%20corporate\%20bonds\%20response\%20to\%20CESR\%20FINAL\%204June2010.pdf

${ }^{2}$ Source: Financial News. http://www.efinancialnews.com/story/2011-08-08/bond-trading-electronic-revolution
} 
sharp disagreement provides the basis for our question of whether and, if so, how an increase in pre-trade transparency will affect OTC markets.

We address this question by constructing a search model and test the model implications in corporate bond markets. We conclude that greater pre-trade transparency improves market liquidity and increases the gains from trade. Our explanation for this finding is that pre-trade information enhances the competitive position of traders in their bargaining with dealers. Specifically, greater pre-trade transparency refines traders' information sets and increases the value of search, making traders become more patient in OTC trading. Consequently, when a trader meets an OTC dealer, the latter has to lower his ask price or increase his bid price to stop his customer, the trader, from leaving for another dealer. As the bid-ask spread narrows, more and more traders participate, thereby increasing market liquidity. In addition, the shrinking bidask spread increases gains from trades.

In our search model, we classify traders as facing Knightian uncertainty in their searches when the OTC market fails to provide complete pre-trade information. Unlike risk, where the odds of future states are known, Knightian uncertainty refers to the situation when the odds of future states are unknown. In decision theory, a decision maker would face Knightian uncertainty if he is unable to form a unique prior. The reason can be vagueness of information (Ellsberg (1961)), or lack of expertise (Easley and O'Hara (2009), Easley and O'Hara (2010b)), or the use of incorrect models to describe the status of the world (Hansen and Sargent (2001)).

We believe that framing the lack of pre-trade transparency as traders searching with Knightian uncertainty is not only novel but also useful. In OTC markets, most transactions are facilitated by dealers. Dealers convey their quotes and negotiate execution prices over the telephone or internet messaging systems. This process of negotiating over trades is known as bilateral trading. In contrast to centralized trading, where pre-trade information is available through the limit order book, pre-trade information in bilateral trading is characterized by information that is exclusive to the two sides of the trade. In addition, quotes provided by dealers are only "as good as the breath is warm." This prevents the trader from collecting pre-trade information by searching through all dealers. The bilateral negotiation and limited information on quotes imply that traders are unable to obtain pre-trade information in OTC markets. More importantly, traders are aware of the absence of pre-trade information. The lack of pre-trade 
information and the awareness of this deficiency indicate the vagueness of information possessed by traders, which gives credit to Knightian uncertainty in the search process.

Furthermore, we assume that traders use max-min preferences to make their trading decisions. The max-min preference requires a decision maker to pay special attention to the worst case scenario. This is consistent with observed behaviors such as "stress testing" and "value-at-risk" taken by financial institutions. Since most traders in OTC markets are financial institutions, this assumption is consistent with reality. An alternative interpretation of Knightian uncertainty and max-min preferences is that traders adopt robust trading strategies to protect themselves against potential misspecification of dealers' trading strategies, since they acknowledge the absence of pre-trade information. The adoption of a search model in our paper is to capture bilateral trading relationships in OTC markets. Bilateral trading requires traders to contact dealers searching for the optimal price. This trading mechanism maps well to a search model in which economic agents seek out the optimal deal.

Besides demonstrating our intuition with the search model, we test our model implications by investigating the impact of pre-trade transparency on bid-ask spreads in corporate bond markets. Our test group consists of bonds that are traded in OTC markets and on the NYSE at the same time. We identify our control group by matching bonds, which are only traded in OTC markets, with the test group. We conduct the match by issuers in the univariate analysis and by a series of bond features and firm characteristics in the multivariate analyses. Since the NYSE's limit order book trading system disseminates pre-trade information, our test group is pre-trade transparent. In contrast to the NYSE, OTC markets do not provide any pretrade information. Therefore our control group is not pre-trade transparent. In the univariate analysis, where we match bonds by issuers, the test group has on average 25 basis points smaller effective bid-ask spreads than the control group. The finding is consistent across different rating categories. After using propensity score matching to acquire a sample of bonds with similar characteristics to NYSE listed bonds, the bid-ask spreads of the test group are still statistically and economically (six and eleven basis points in two different logistic regression models, respectively) lower than the control group. In our sample period, bond transactions are roughly $\$ 850$ billion per year. This means that if pre-trade transparency had been offered as part of OTC trading, investors would have saved approximately $\$ 930$ million per year on transaction costs. Results from multivariate regressions show that pre-trade transparent bonds have significantly 
lower bid-ask spreads than non-pre-trade transparent bonds after controlling for bond features and firm characteristics. To conclude, our empirical studies find that pre-trade transparency benefits OTC markets by reducing bid-ask spreads. This supports the implication from our theoretical model.

The next section reviews the related literature. Section 3 presents the model of the search equilibrium in an OTC market. In Section 4, we conduct an empirical exercise on the corporate bond markets to test the implications of our model. Section 5 provides a discussion of our paper's implications. Finally, Section 6 concludes the paper and discusses its limitations.

\section{Related Literature}

Our paper adds to the literature on the relationship between pre-trade transparency and market quality. This relationship is important to the design of markets, since it provides implications on market liquidity, informational efficiency, inter-market competition, and ultimately the welfare of market participants. However, academia has not yet reached an agreement on major issues in these areas. Boehmer, Saar and $\mathrm{Yu}$ (2005) find that the introduction of NYSE's OpenBook service, which provides limit-order book information, decreases the price impact of orders and improves the informational efficiency of prices. Eom, Ok and Park (2007) find that market stability and informational efficiency of the price are improved when the Korea Exchange increases the number of publicly disclosed quotes. On the other hand, Madhavan, Porter and Weaver (2005) find that increased pre-trade transparency leads to higher trading costs and volatility after the Toronto Stock Exchange disseminated realtime information on its limit order book to the public. In addition, scholars attempt to understand the influence of pre-trade transparency with experimental studies. Those experimental studies do not converge either. Bloomfield and O'Hara (1999) show that pre-trade transparency has no impact on market quality, whereas Flood, Huisman, Koedijk and Mahieu (1999) conclude that it improves market quality. All prior research except the experiment of Flood, Huisman, Koedijk and Mahieu (1999) focuses primarily on exchange trading. However, no theoretical or empirical work has been done to understand how pre-trade transparency affects the quality of OTC trading. Our paper fills this gap. We find that pre-trade transparency increases market liquidity, market participation, and gains from trades in OTC trading. 
Our beneficial conclusion for the increase in pre-trade transparency reiterates the importance of recent financial reform designed to enhance the transparency of OTC markets. While Acharya and Bisin (2010) focus on reducing counterparty risks, and Zhu (2011) focuses on improving the efficiency of the price discovery, we emphasize another benefit from increasing transparency - specifically, greater market participation and higher liquidity.

Our paper also belongs to the growing literature on ambiguity or Knightian uncertainty in market microstructure research. The relevance of Knightian uncertainty in market microstructure studies is pointed out by O'Hara (2007), where she claims that an optimal market microstructure should be embedded with designs to reduce ambiguity, or Knightian uncertainty. Studies on exchange trading (Easley and O’Hara (2009), Easley and O'Hara (2010a), Easley and O'Hara (2010b)) show that certain features of the market organization and the regulations over unlikely events can lessen the perceived Knightian uncertainty, which in turn increases market participation and liquidity. We contribute to this strand of literature with findings on OTC markets. Given the different trading environments considered, we provide a different policy suggestion on reducing Knightian uncertainty - namely to increase pre-trade transparency and, by extension, enhance market participation and improve liquidity.

With the consideration of Knightian uncertainty in the search process, our theoretical model extends the work by Spulber (1996) and Rust and Hall (2003). Besides using the discount factor to capture the delay cost in search, we implicitly consider Knightian uncertainty as another layer of the search cost. The closest model to ours is that of Nishimura and Ozaki (2004) where they consider Knightian uncertainty in the job search. However, the assumption of exogenous prices (wages) in Nishimura and Ozaki (2004) limits their analysis of the effect of Knightian uncertainty on prices. Our model with endogenously-determined prices allows us to understand how Knightian uncertainty affects prices.

The search formulation in our model is different from Duffie, Garleanu and Pedersen (2005), and Duffie, Garleanu and Pedersen (2007). In those papers, both traders and dealers search, whereas in our paper, only traders search, and they search through unknown price distributions. Both types of models are adequate to capture the search friction in OTC markets, but our model has the advantage of parameterizing transparency in OTC trading through the uncertainty of price distributions. 
In addition, our search model extends the inventory literature. Most inventory models assume an exogenous process on demand and supply received by dealers (e.g. Garman (1976), Amihud and Mendelson (1980), and others). Though this assumption simplifies the solution of those models (since the equilibrium asks and bids are determined solely by dealers), it ignores how traders affect equilibrium prices. We endogenize demand and supply by deriving them from traders' optimal strategies. This enables us to investigate the interaction between traders and dealers, and hence retrieve equilibrium prices.

Lastly but not the least, our empirical work complements studies on the connection between price transparency and liquidity in the corporate bond market. Bessembinder, Maxwell and Venkataraman (2006), Edwards, Harris and Piwowar (2007), and Goldstein, Hotchkiss and Sirri (2007) find that post-trade transparency improves market liquidity. We show that pre-trade transparency also increases market liquidity.

\section{The Search Equilibrium in the OTC Market}

In a simple exchange economy where the dealer is the only intermediary, there are three types of agents, namely the buying trader, the selling trader, and the dealer. Traders are heterogeneous in their internal valuations $v$. More specifically, $v^{B}$ for the buyer, $v^{S}$ for the seller, both of which follow the uniform distribution over $[0,1]$. The dealer is heterogeneous in their transaction costs $k$, which follow the uniform distribution over $[0,1]$. We do not model the heterogeneity among traders explicitly. This assumption is a reduced description of various reasons that prompt traders to trade. Transaction costs are expenses for dealers to maintain preferred inventory levels as in the inventory literature. Due to different risk capacities, dealers' preferred inventory positions are different, which implies heterogeneity in transaction costs among dealers. In addition, transaction costs also include operational fees or expenses of innovating financial products. ${ }^{3}$ Thus, the heterogeneity in dealers' transaction costs can also be interpreted as the variation of dealers' professional knowledge and special training in facilitating

\footnotetext{
${ }^{3}$ Unlike equity trading, in which traded assets are standardized, most OTC markets are usually for trades of customized products. Making a market for those tailored products requires professional knowledge and special training, both of which could incur a substantial cost. In addition, dealers sometimes create an OTC market by inventing a new financial product. The considerable expenses associated with innovation are partially covered by bid-ask spreads charged by dealers in intermediating trades over the new product.
} 
trades. Assuming the dealer is the only intermediary captures the essence of the OTC market: there is no central exchange where assets are traded publicly. In the OTC market, the only way for traders to obtain quotes is to contact individual dealers - specifically, one randomly picked dealer for every round of contact. Thus, transactions in the OTC market are carried out over a range of individually negotiated prices resulting from a costly sequential search process.

The dealer is infinitely lived and sets bid and ask prices to maximize expected profit. Traders, who have max-min preferences, engage in the sequential search process with Knightian uncertainty. The set of priors available to traders is an $\epsilon$-contamination of the historical distributions over bid and ask prices. ${ }^{4}$ In particular, for any given $\epsilon$, the buyer is endowed with the following set of priors,

$$
\boldsymbol{P}^{B}(\epsilon) \equiv\left\{(1-\epsilon) P_{a}+\epsilon \mu: \mu \in \boldsymbol{M}\right\},
$$

where $P_{a}$ is the historical distribution of ask prices and $\boldsymbol{M}$ is the set of all probability measures on the Borel set of real numbers. Sellers are endowed with the following set of priors,

$$
\boldsymbol{P}^{\boldsymbol{S}}(\epsilon) \equiv\left\{(1-\epsilon) P_{b}+\epsilon \mu: \mu \in \boldsymbol{M}\right\},
$$

where $P_{b}$ is the historical distribution of bid prices and $\boldsymbol{M}$ is the set of all probability measures on the Borel set of real numbers. In either $\boldsymbol{P}^{\boldsymbol{B}}(\epsilon)$ or $\boldsymbol{P}^{S}(\epsilon)$, when $\epsilon$ is zero, the set consists of a unique prior which means no Knightian uncertainty; as $\epsilon$ becomes larger, the level of Knightian uncertainty increases. As Knightian uncertainty represents the lack of transparency, $\epsilon$ measures the degree of transparency in OTC trading. Specifically, when the OTC market is fully transparent, traders face no Knightian uncertainty in their searches, i.e., $\epsilon$ is zero; when the OTC market becomes less transparent, traders face larger Knightian uncertainty, i.e., $\epsilon$ increases; and when the OTC market becomes completely opaque, traders face enormous Knightian uncertainty, i.e., $\epsilon$ equals one. This $\epsilon$-contamination specification not only measures the OTC market transparency with its radius $\epsilon$, but also incorporates historical ask and bid price information with its core $P_{a}$ and $P_{b}$ elements, respectively. In other words, traders construct their priors by contaminating the distributions of historical prices, and how severe they contaminate the distributions depends on the transparency of the OTC market. We restrict both buyers and sellers to face the same level of Knightian uncertainty. This is because we use Knightian

\footnotetext{
${ }^{4}$ The $\epsilon$-contamination refers to the procedure of introducing a set of priors by contaminating a single hypothetical prior with an $\epsilon$ probability ball around it. To be more specific,$$
\boldsymbol{P}(\epsilon) \equiv\left\{(1-\epsilon) P_{0}+\epsilon \mu: \mu \in \boldsymbol{M}\right\},
$$

where $P_{0}$ is the hypothetical prior and $\mu$ is any probability distribution in the relevant space.
} 
uncertainty as the description of the trading environment rather than the source of heterogeneity among OTC traders. We acknowledge that we are making an implicit assumption to equate the $\epsilon$-contamination to Knightian uncertainty, since the former is a special case of the latter. However, we believe implications obtained with the $\epsilon$-contamination would still hold under a more general specification of Knightian uncertainty. Both dealers and traders discount future payoffs with $\beta$.

\subsection{The Trader's Decision}

For any given $\epsilon$, a buyer is trying to maximize his minimal expected future payoff,

$$
\min \left\{\int I(a) d P: P \in \boldsymbol{P}^{\boldsymbol{B}}(\epsilon)\right\}
$$

where $I(a)$ is the discounted future payoff. More specifically, $I(a)=\beta^{t}\left(v^{B}-a\right)$ if he trades at time $t$, or zero otherwise. That is,

$$
I(a)= \begin{cases}\beta^{t}\left(v^{B}-a\right), & \text { if he trades at time } t ; \\ 0 & \text { otherwise. }\end{cases}
$$

By Schmeidler (1989), the buyer's objective function equals the Choquet integral of discounted future payoffs $I(a)$ with respect to a convex probability capacity $\theta_{a}$, which means

$$
\min \left\{\int I(a) d P: P \in \boldsymbol{P}^{\boldsymbol{B}}(\epsilon)\right\}=\int I(a) d \theta_{a} .
$$

For any given measurable set $E, \theta_{a}$ is,

In the above, $\Omega$ represents all asks.

$$
\theta_{a}(E)= \begin{cases}(1-\epsilon) P_{a}(E) & , \text { if } E \neq \Omega \\ 1 & \text {, if } E=\Omega\end{cases}
$$

As shown in Nishimura and Ozaki (2004), the Bellman equation associated with the above problem is,

$$
V^{B}\left(a, v^{B}\right)=\max \left\{0, v^{B}-a, \beta \int V^{B}\left(\hat{a}, v^{B}\right) d \theta_{a}\right\} .
$$

In the above equation, $V^{B}(a)$ is the value function for the buyer who has an ask offer $a$ in hand, while $\hat{a}$ is his next randomly received ask if he continues to search. The Bellman equation reflects the choices that the buyer has: (i) do nothing; (ii) accept the dealer's ask and close the deal; or (iii) reject the ask price and continue to search. Obviously, if the buyer has $v^{B} \leq \underline{a}$ ( $\underline{a}$ is the lower bound of the ask prices offered by dealers), he will never trade or search in the market. ${ }^{5}$ When $v^{B}>\underline{a}$, the optimal search strategy for the buyer is to accept any ask greater

\footnotetext{
${ }^{5}$ For technical reasons, we assume that when a trader is indifferent between trading in the market or not, he chooses
} 
than his reservation buying price. The reservation buying price $r^{B}\left(v^{B}\right)$ is defined implicitly as follows,

$$
v^{B}=r^{B}\left(v^{B}\right)+\frac{\beta}{1-\beta} \int_{\underline{a}}^{r^{B}\left(v^{B}\right)} \theta_{a}[a \leq \hat{a}] d \hat{a} .
$$

According to Nishimura and Ozaki (2004), the reservation buying price can be shown as follows,

$$
v^{B}=r^{B}\left(v^{B}\right)+\frac{\beta(1-\epsilon)}{1-\beta} \int_{\underline{a}}^{r^{B}\left(v^{B}\right)} P_{a}[a \leq \hat{a}] d \hat{a} .
$$

Define $\underline{v}^{B}$ as the valuation of the marginal buyer for whom the gain from entering the OTC market is zero. Thus, $\underline{v}^{B}=\underline{a}=r^{B}\left(\underline{v}^{B}\right)$. Applying the Implicit Function Theorem, we can show that $r^{B}\left(v^{B}\right)$ is a strictly increasing function of $v^{B}$ on the interval $\left(\underline{v}^{B}, 1\right]$.

Similarly, for the seller, his reservation price is

$$
v^{S}=r^{S}\left(v^{S}\right)-\frac{\beta(1-\epsilon)}{1-\beta} \int_{r^{S}\left(v^{S}\right)}^{\bar{b}} P_{b}[b \geq \hat{b}] d \hat{b} .
$$

And $r^{S}\left(v^{S}\right)$ strictly increases on the interval $\left[0, \bar{v}^{S}\right) \cdot \bar{v}^{S}$ denotes to the valuation of the marginal seller, whose gain from trading is zero, i.e., $\bar{v}^{S}=\bar{b}=r^{S}\left(\bar{v}^{S}\right)$.

\subsection{The Dealer's Decision}

Since $v^{B}$ is uniformly distributed on $\left(\underline{v}^{B}, 1\right]$ and $r^{B}\left(v^{B}\right)$ is monotone on the interval $\left(\underline{v}^{B}, 1\right]$, by the change of variables, the density of reservation buying prices is

$$
f^{B}\left(r^{B}\right)=\frac{1-\beta+F_{a}\left(r^{B}\right)(1-\epsilon) \beta}{(1-\beta)\left(1-\underline{v}^{B}\right)} .
$$

Analogously, the density of reservation selling prices is

$$
f^{S}\left(r^{S}\right)=\frac{1-\beta+\left(1-F_{b}\left(r^{S}\right)\right)(1-\epsilon) \beta}{(1-\beta) \bar{v}^{S}} .
$$

A dealer posts a pair of stationary bid and ask prices to maximize his expected discounted profits. The dealer is constrained by keeping expected supply equal to expected demand, because of the assumption that dealers carry no inventory across successive periods. ${ }^{6}$

As $N$ is the total mass of dealers operating in the market, $\frac{1-\underline{v}^{B}}{N} f^{B}\left(r^{B}\right)$ represents the

not to trade. That is, when a buyer has valuation $v^{B}=\underline{a}$ he quits, and when a seller has valuation $v^{S}=\bar{b}$ he quits. $\bar{b}$ is the upper bound of bids offered by dealers.

${ }^{6}$ The same assumption is made in Spulber (1996), Rust and Hall (2003), Duffie, Garleanu and Pedersen (2005), Duffie, Garleanu and Pedersen (2007), and Lagos and Rocheteau (2009). 
density of buyers for every dealer. The number of buyers, who have reservation price $r^{B}$, visiting the dealer is as follows: 1 at date- $0, P_{a}\left[a \geq r^{B}\right]$ at date- $1, P_{a}^{2}\left[a \geq r^{B}\right]$ at date-2, ..., $P_{a}^{t}\left[a \geq r^{B}\right]$ at date- $t$. If the dealer sets the ask to $a$, then the market demand at time $t$ is

$$
\begin{aligned}
& D_{t}(a)=\frac{1-\underline{v}^{B}}{N} \int_{a}^{r^{B}(1)} P_{a}^{t}\left[a \geq r^{B}\right] f^{B}\left(r^{B}\right) d r^{B} \\
& =\frac{1}{N} \int_{a}^{r^{B}(1)} \frac{\left(1-F_{a}\left(r^{B}\right)\right)^{t}\left(1-\beta+F_{a}\left(r^{B}\right)(1-\epsilon) \beta\right)}{1-\beta} d r^{B},
\end{aligned}
$$

By an analogous derivation, the date-t supply associated with the bid price $b$ is,

$$
S_{t}(b)=\frac{1}{N} \int_{r^{s}(0)}^{b} \frac{F_{b}^{t}\left(r^{S}\right)\left(1-\beta+\left(1-F_{b}\left(r^{S}\right)\right)(1-\epsilon) \beta\right)}{1-\beta} d r^{S},
$$

Given demand $D_{t}(a)$ and supply $S_{t}(b)$, the dealer's objective is

$$
\max _{\mathrm{a}, \mathrm{b}} \sum_{t=0}^{\infty} \beta^{t}\left(a D_{t}(a)-(b+k) S_{t}(b)\right)
$$

subject to

$$
D_{t}(a)=S_{t}(b)
$$

\subsection{The Stationary Search Equilibrium}

With traders maximizing their minimum payoffs, and the dealer maximizing his profit, we have the stationary search equilibrium in the OTC market.

\section{Proposition 1}

For any given $\epsilon$, there exists a continuously differentiable symmetric equilibrium pricing policy, $a(k), b(k)$, with $a(k)$ increasing and $b(k)$ decreasing in $k$ for all $\underline{k} \leq k<k^{*}$. Where $k^{*}$ denotes the marginal dealer whose profit margin and trading volume are zeros. The pricing policy functions satisfy

$$
\begin{gathered}
a(k)=e^{-\int_{k}^{k^{*}} Y(z) d z}\left(\frac{k^{*}+1}{2}\right. \\
\left.+\int_{k}^{k^{*}}\left(-\frac{1}{4}+\frac{1+z}{2} Y(z)\right) e^{\int_{z}^{k^{*}} Y(u) d u} d z\right), \\
b(k)=1-a(k), \\
k^{*}=a\left(k^{*}\right)-b\left(k^{*}\right),
\end{gathered}
$$

where 


$$
Y(z)=\frac{\beta}{2\left(k^{*}-\underline{k}\right)}\left(\frac{1}{1-\frac{\beta\left(k^{*}-z\right)}{k^{*}-\underline{k}}}-\frac{1-\epsilon}{1-\beta+\frac{z-k}{k^{*}-\underline{k}}(1-\epsilon) \beta}\right),
$$

and $k^{*}$ is the solution of the following equation

$$
1=\frac{k^{*}+1}{2}+\frac{\beta(1-\epsilon)}{1-\beta}\left(\frac{k^{*}+1}{2}-\frac{1}{k^{*}-\underline{k}} \int_{\underline{k}}^{k^{*}} a(k) d k\right) .
$$

In the stationary equilibrium, the historical distribution of prices coincides with the equilibrium distribution of prices. The equilibrium obtained in our model is similar to the rational expectations equilibrium concept as the equilibrium prices are within traders' sets of priors. But in terms of equilibrium outcomes, our equilibrium is different from the rational expectations equilibrium. The difference is that traders' predictions on prices systematically deviate from equilibrium prices, and the deviation is characterized by the $\epsilon$-contamination of the equilibrium price. The systematic deviation depends on the transparency in the OTC market. When the OTC market is fully transparent, our equilibrium becomes the rational expectations equilibrium obtained in Spulber (1996) as traders' sets of priors implode to singletons which are equilibrium prices.

\subsection{Comparative Statics}

As the price system is non-linear, we can only demonstrate the comparative statics numerically. Setting $\beta=0.9$ and $\underline{k}=0.005$, we solve the equilibrium with $\epsilon$ ranges from 0 to $0.5{ }^{7}$ Figure 1 shows that the average bid-ask spread decreases as $\epsilon$ decreases. And the right panel of Figure 2 shows that the total mass of traders in the OTC market increases as $\epsilon$ decreases. The shrinking average spread and the increasing participation imply that market liquidity increases as $\epsilon$ decreases. In other words, more transparency increases market liquidity. However, the decreasing average spread reduces dealers' profit margins, discouraging more dealers to join in the market. The left panel of Figure 2 shows that the total mass of dealers in the market decreases as $\epsilon$ decreases.

To understand those results, we compare ask prices when the OTC market is transparent (that is, when $\epsilon=0$ ) with ask prices when the OTC market is less transparent (that is, when $\epsilon>$

\footnotetext{
${ }^{7}$ We obtain similar results with other assigned parameter values.
} 
0 ). Figure 3 shows that the cumulative density function of asks shifts toward the left when $\epsilon=$ 0 . The shift means that as the market becomes transparent buyers are more likely to receive lower asks from dealers. Since in equilibrium, $b(k)=1-a(k)$, the dealer who lowers his ask also increases his bid. Hence, when the market is transparent, all operating dealers' bid-ask spreads $a(k)-b(k)$ become smaller. The average spread decreases. Consequently, the shrinking bid-ask spreads encourage more traders to participate.

Shrinking bid-ask spreads are due to the change in traders' perceptions of their outside options. When the OTC market becomes transparent, traders are more certain about their search processes, which enhance their confidence in finding better offers from dealers. Traders are more willing to search. Figure 4 shows that buyers' reservation buying prices decreases and sellers' reservation selling prices increases when $\epsilon=0$. That is, buyers demand to buy at lower prices and sellers demand to sell at higher prices. These reflect the notion that as search value increases, traders are at better bargaining positions against dealers. Dealers are forced to accommodate to buyers and sellers' changes of reservation prices. In other words, a dealer must decrease his ask price to prevent buyers from leaving for another dealer. Likewise, a dealer must increase his bid price to prevent sellers from leaving for another dealer. Finally, we see smaller bid-ask spreads arise as a result of increasing search value, when the market is transparent.

\subsection{The Welfare Analysis}

We define the gains from trade as the sum of traders' surplus

$$
\int_{\underline{v}^{B}}^{1}\left(v^{B}-r^{B}\left(v^{B}\right) d v^{B}+\int_{0}^{\bar{v}^{S}}\left(r^{S}\left(v^{S}\right)-v^{S}\right) d v^{S} .\right.
$$

The left panel of Figure $\overline{5}$ shows that as $\epsilon$ decreases, traders' surplus increases. This means that the gains from trade increase as the market becomes more transparent. While traders benefit from a more transparent market, dealers suffer from transparency. In the right panel of Figure 5, we find that dealers' total profit decreases as $\epsilon$ decreases.

\section{The Empirical Exercise on the Corporate Bond Market}

In Section 3, we show that the average bid-ask spread decreases as pre-trade transparency increases (see Figure 1). In this section, we conduct a controlled experiment on the corporate bond market to test this implication. 


\subsection{Data and Sample}

We collect firm characteristics data from COMPUSTAT, bond transactions data from Trade Reporting and Compliance Engine (TRACE), and bond characteristics data from Mergent Fixed Income Securities Database (FISD). An important file we obtain from FISD is the "ISSUE EXCHANGE" master file. This file documents the exchange(s) (if any) where the bonds are listed. Hence, we are able to identify OTC traded bonds which are also traded on the NYSE. Table 1 describes the sample selection procedure. Our initial sample ranges from November 1 , 2008 to March 31, 2011 and includes 40,977 bonds with 26,658,403 trades and \$7.6 trillion of volume. We filter the data by eliminating put-able bonds, bonds with abnormal prices (prices greater than $\$ 200$ or less than $\$ 10$ ), bonds with subsequent corrections, and bonds affected by price reversions. ${ }^{8}$ To compute same-bond-same-day effective bid-ask spreads, we further require bonds to have at least one buy and one sell transaction within a day as in Hong and Warga (2000), and Chakravarty and Sarkar (2003). Lastly, we drop all bonds that are listed on an exchange other than the NYSE. ${ }^{9}$ The final sample used for our empirical analysis has 21,789 bonds with 10,476,166 trades and $\$ 3.7$ trillion of volume.

\subsection{The Estimation of Effective Bid-ask Spreads}

The relation between transparency and liquidity is a pertinent issue in bond markets. In this paper, we investigate whether greater transparency in the corporate bond market with respect to pre-trade quote information leads to better liquidity as measured by lower bid-ask spreads. Since the quotation data for corporate bond trading is generally unobtainable, we have to estimate effective bid-ask spreads using transaction records. There are two approaches to estimate the effective bid-ask spreads. The first approach, used by Hong and Warga (2000), Chakravarty and Sarkar (2003), and others, is to calculate the "traded bid-ask spreads" over a one-day window in the corporate bond market. Specifically, this approach takes the average of

\footnotetext{
${ }^{8}$ Denote the bond return from time $t$ to time $t+1$ as $R_{t}^{t+1}$, a price reversion happens if $R_{-1}^{0}<-10 \%$ and $R_{0}^{1}>$ $-0.5 R_{-1}^{0}$ or if $R_{-1}^{0}>10 \%$ and $R_{0}^{1}<-0.5 R_{-1}^{0}$. We adjust our filter rule from Bessembinder, Kahle, Maxwell and $\mathrm{Xu}(2009)$.

${ }^{9}$ The empirical results are not affected at all even if we include those bonds listed on exchanges other than the NYSE.
} 
differences between selling prices and buying prices on the same day as the effective bid-ask spread. The second approach, adopted by Schultz (2001), Edwards, Harris and Piwowar (2007), and others, relies on a regression-based method that takes liquidity into consideration. Both approaches yield the same results on the determinants of effective spreads, and hence, are mutually consistent. ${ }^{10}$ Though we apply the first approach in our estimation of effective spreads, our multiple regression results are consistent with findings in Edwards, Harris and Piwowar (2007) with respect to the sign and significance level of estimated coefficients. This suggests that our empirical results are robust to the estimation method of effective bid-ask spreads used by Edwards, Harris and Piwowar (2007).

We estimate the effective bid-ask spread for a particular bond as the time series average of its traded bid-ask spreads in a one-day window. The traded bid-ask spread is the difference between the average daily selling price and average daily buying price divided by their sum:

1. Denoting $i$ to each individual bond and $t$ to time periods, we have

$$
\text { Spread }_{i t}=\frac{\overline{\operatorname{Sell}}_{i t}-\overline{B u y}_{i t}}{\overline{\operatorname{Sell}}_{i t}+\overline{B u y}_{i t}},
$$

where $\overline{\operatorname{Sell}}_{i t}$ and $\overline{B u y}_{i t}$ are the average daily selling price and buying price, respectively.

2. Taking the time series average of Spread $_{i t}$, we have

$$
\text { Spread }_{i t}=\sum_{t=1}^{T_{i}} \frac{\text { Spread }_{i t}}{T_{i}},
$$

where $T_{i}$ is the time length of the bonds in our sample.

\subsection{The Controlled Experiment}

The NYSE Bonds trading system is a transparent electronic limit-order market which provides participants with a complete quotation at each buy and sell price. In contrast, OTC markets provide little pre-trade information. Given this difference, corporate bonds traded both on the NYSE and in OTC markets are more pre-trade transparent than those traded only in OTC

\footnotetext{
${ }^{10}$ For details, see Edwards, Harris and Piwowar (2007).
} 
markets. To explore how this difference affects corporate bonds trading, we design a controlled experiment. The test group consists of bonds traded both on the NYSE and in OTC markets, namely OTC-NYSE. The control group consists of bonds only traded in OTC markets, namely OTC-only. Our null hypothesis is:

Hypothesis 2 The average effective bid-ask spreads in the test group (OTC-NYSE) are the same as the average effective bid-ask spreads in the control group (OTC-only).

Our controlled experiment overcomes the empirical challenge in studying the influence of transparency. In general, to study the influence of transparency, researchers compare the transaction costs before and after real-world events in which the disclosure policy changes market transparency. These events are rare. As a result, there is little evidence about the impact of pre-trade transparency on financial markets, especially OTC markets. In this paper, we differentiate bonds' pre-trade transparent regimes by identifying whether they are traded on the NYSE or not. More importantly, we control for bond and firm characteristics in both univariate and multivariate regression analyses. In so doing, we control for the sample selection bias that can arise in our controlled experiment.

\subsection{Empirical Results on the Difference of Bid-ask Spreads between Bonds with and without Pre-trade Information}

In this subsection, we show the results of comparing the bid-ask spreads of the test group (OTC-NYSE) and the control group (OTC-only). Firstly, we focus on bonds issued by the same firm to control for firm characteristics; secondly, we match bonds based on a group of bond features and firm characteristics using bonds' propensity scores to control for sample selection bias in our controlled experiment; thirdly, we compare our results with Edwards, Harris and Piwowar (2007) with multiple regression analysis. We obtain consistent results in all the above procedures. Our results suggest that pre-trade transparency reduces effective bid-ask spreads in corporate bond trading. This result is consistent with the theoretical implication in Section 3.

\subsubsection{Bonds Issued by the Same Firm}


In Table 2, we compare the average effective bid-ask spreads of bonds issued by the same firm. The number of bonds varies due to the availability of variables in datasets. The number of non-investment bonds is much smaller than the number of investment bonds in both groups. This is consistent with the notion that rating agencies are more willing to assign investment ratings to corporate bonds. We find that bonds traded in OTC markets and on the NYSE have smaller bidask spreads than bonds exclusively traded in OTC markets. For the total sample in Table 2, the average bid-ask spread for OTC-NYSE group bonds is 25 basis points lower than those of OTConly group bonds. The difference is highly statistically and economically significant. In our data, the trading volume is approximately $\$ 850$ billion per year for OTC-only bonds. This implies a minimum of $\$ 2$ billion per year could have been saved if pre-trade quotations of bonds had been disclosed. In addition, we obtain consistent findings across different credit categories. We find that the difference of bid-ask spreads in non-investment bonds is 52 basis points, which is much greater than the difference in superior bonds (with a value of 31 basis points) and other investment bonds (with a value of 21 basis points). Both differences are statistically significant.

Results in Table 2 imply that pre-trade information decreases bid-ask spreads in corporate bond trading. The reduction is more evident for low credit rating bonds than high credit rating bonds. However, we acknowledge these results can be influenced by sample selection bias. That is, the difference in bid-ask spreads between the OTC-NYSE group and the OTC-only group may depend on bond and firm characteristics that are related to whether or not firms choose or are chosen to list bonds on the NYSE. ${ }^{11}$ The sample selection bias will lead to biased estimates of the pre-trade transparency effect which can favor our conclusion. To control for the sample selection bias, we use propensity score matching.

\subsubsection{Bonds Matched by Propensity Scores}

We use propensity score matching to acquire a sample of bonds with similar characteristics to bonds traded both in OTC markets and on the NYSE (but the sample contains

\footnotetext{
${ }^{11}$ The number of bonds within the OTC-only bonds in Table 2 is far greater than that of OTC-NYSE bonds. This implies that firms choose to trade fewer bonds on the NYSE than in OTC markets. Also the coupon rate between the OTC-only group and OTC-NYSE group differs dramatically. It could be that firms choose bonds which are more liquid to trade on the NYSE. This endogeneity problem suggests our findings could be biased.
} 
bonds traded only in OTC markets). We first run logistic regressions to determine what factors influence firms' listing decisions on their bonds. Using the estimated coefficients, we can obtain the predicted probability (propensity score) for each bond. After that, we match each OTCNYSE bond to an OTC-only bond based on the closest propensity score. We present results in Table 4.

We attempt to model firms' listing decisions on their bonds from two perspectives: firm characteristics and bond features. There has been no research on how firms decide to list bonds on the NYSE versus in OTC markets. We construct our model based on some basic intuition and studies of foreign firms' preferences on the U.S. bond market. We control for the following firm characteristics: size, leverage ratio, equity listing status, and accounting standard. Size matters because large firms have lower costs to meet strict disclosure requirements and thus are more likely to list bonds on the NYSE. Equity listing status affects bond listing choice since private firms are less likely to list bonds on the NYSE as they fail to meet the strict disclosure requirements imposed by the exchange. In addition, cross listing studies show that foreign firms listing equities on the U.S. stock exchanges are more likely to choose the U.S. bond market (Miller and Puthenpurackal, 2002). For the accounting standard, Gao (2011) shows that firms adopting International Financial Reporting Standards prefer the U.S. public bond market. Bond features, which complicate the valuation of bonds, may also affect firms' decisions. For example, retail investors, who dominate the NYSE may prefer a standard payment bond to a non-standard one. This clientele effect can impact firms' decisions on whether or not to list their bonds on the NYSE. In Table 3, we present our choice variables and their definitions.

Panel A in Table 4 presents our logistic regression results of firms' decisions to list bonds on the NYSE. The dependent variables are binary variables with a value of 1 if a bond is listed on the NYSE and is 0 otherwise.

Consistent with our conjecture, we find that firms listing bonds on the NYSE are larger and more likely to be publicly listed. Large firms have better information disclosure and coverage than small ones. It is less costly for large firms to list bonds on the exchange. On the other hand, private firms are less likely to list their bonds on the NYSE due to the stringent requirements of the exchange. We are also interested in whether listing equities on the NYSE would incentivize firms to list their bonds on the NYSE, since having equities on the NYSE may 
reduce the information disclosure cost of listing bonds on the NYSE. In untabulated results, we replace the dummy variable representing whether a firm is private by the dummy variable indicating whether a firm is listed on the NYSE. Surprisingly, an issuer, with stocks listed on the NYSE, is less likely to have bonds listed on the NYSE. This runs counter to the notions that (1) the NYSE may place fewer additional disclosure requirements on firms, who already trade equities on the exchange, and (2) the additional reporting costs on bonds on the NYSE are trivial for firms with equities listed on the NYSE. Both of these will make the listing easier.

Gao (2011) finds that firms adopting International Financial Reporting Standards prefer to list bonds on the U.S. public bond market but she does not differentiate whether it is in OTC markets or on the NYSE. In Table 4, we find that accounting standards do not pose any effect on the choice of bond markets given that all three coefficients are not statistically significant. In addition, the leverage ratio does not affect firms' choices either.

Bonds with low coupon rates are more likely to be listed on the NYSE. This reflects the clientele effect. Low coupon payment bonds are usually associated with lower risks, and hence, their primary clients are retail investors, who prefer to trade on the exchange. In addition, we find that bonds with smaller issue size or shorter maturities are more likely to be issued on the exchange.

We find that the probability of listing bonds on the NYSE is positively correlated with Moody's bond rating. This indicates that the probability increases as credit quality decreases. This relation also holds when we use the indicator of investment grade bonds as a proxy for bonds' credit quality. As low rating bonds are less preferred by investors and are more difficult to sell than high rating bonds, the positive relation between the listing probability and the Moody's rating indicates firms' attempts to promote the sale of low rating bonds by listing those bonds both on the NYSE and in OTC markets. The positive correlation between the probability of listing bonds on the NYSE and Moody's rating also reflects that the information disclosure required by the exchange helps investors to better value bonds. As a result, poorly rated bonds benefit more than highly rated bonds since poorly rated bonds are more complex to value than highly rated bonds. In addition, from Table 2, we find that listing on the NYSE can increase the liquidity of bonds, and the increase is more evident in non-investment grade bonds, which are 
poorly rated. This suggests that firms will list their lower rating bonds on the NYSE, since the increase in liquidity is associated with a decrease in firms' borrowing costs. ${ }^{12}$

Global bonds are less likely to be listed on the NYSE than domestic bonds. Yankee bonds, U.S. dollar-denominated bonds issued by foreign firms in the U.S. market, are less likely to be listed on the NYSE. Foreign issuers are reluctant to access the U.S. exchange market due to costs incurred by stringent disclosure requirements. Surprisingly, Rule 144a bonds, which are issued by foreign issuers and traded only by large institutions (Qualified Institutional Buyers (QIBS)), are more likely to be listed on the exchange. This suggests that institutional investors push foreign bonds to list themselves on the exchange. By doing so, institutional investors can learn from the required information disclosure and pre-trade information offered by the exchange. This helps institutional investors to better price and trade Rule 144a bonds.

Variable interest payment bonds, with coupon payments adjusting to some schedule or a reference index (for example, LIBOR), are more likely to be listed on the NYSE. One possible explanation is that this feature is somewhat easier to price compared to other bond complexity features like non-cash call, nonstandard payment, etc. Therefore, retail investors, who dominate the NYSE, are willing to bear this risk to earn the premium. The bond with variable interest payments can also timely reflect the change of the lending earnings in the market in response to market pressures. This helps investors, especially retail investors, to manage their investments. This feature is very attractive to investors given our finding in Table 4 and the high transaction costs that investors are willing to pay as shown in Table $5 .{ }^{13}$ The option of calling is negatively correlated with the probability of listing on the NYSE. And nonstandard payment bonds tend to be traded only in OTC markets. Both of these properties indicate that bonds with complicated instruments are too difficult for retail investors to value. Since the majority traders on the NYSE are retail investors, complex bonds will not be favored on the NYSE, and hence, suffer from liquidity shortage. Consistent with this clientele effect, we find that senior bonds, which offer individual traders' priority to claim interest payments, are more likely to be listed on the exchange. Bond issuers in utility industry tend to issue bonds in the only OTC markets.

\footnotetext{
${ }^{12}$ Chen, Lesmond, and Wei (2007) find that the bond yield on investment-grade (high yield) bonds will increases 0.42 (2.3) basis points when the bid-ask spread increases one basis point.

${ }^{13}$ Edwards, Harris and Piwowar (2007) also find that variable rate bonds are slightly expensive to trade than fixed rate bonds.
} 
It seems that bond features are more critical than firm characteristics when firms decide whether or not to list bonds on the NYSE. Overall, our logistic regression results suggest that firms' choices of issuing bonds on the NYSE are positively related to: total assets, Moody's bond rating, variable rate bond, senior bond, Rule 144a bond, and when an issuer is in default. On the other hand, firms' preferences of issuing bonds on the NYSE is negatively related to: whether issuers are private firms, whether issuers' equities are traded on the NYSE, the magnitude of coupon payments, issue size, years to maturity, global bond, foreign bond, callable bond, nonstandard payment bond, and Yankee bond.

Panel B of Table 4 reports the comparison result after we match bonds by their propensity scores. We find that the average effective bid-ask spreads for bonds traded both in OTC markets and on the NYSE is still (about six and eleven basis points in two different regressions, respectively) lower than bonds traded only in OTC markets. The difference is statistically significant at the 0.01 level. Edwards, Harris and Piwowar (2007) find that transaction costs of TRACE-transparent (post-transparent) bonds are five basis points lower than bonds lacking post-transparency. Our data show that in the sample period, approximately $\$ 850$ billion per year is traded on bonds for which pre-trade quote information is not available. These results indicate that a minimum of $\$ 930$ million per year could be saved on transaction costs if pre-trade transparency were to be enforced. Our finding is comparable to Edwards, Harris and Piwowar (2007) who report a minimum number of $\$ 1$ billion could have been saved if post-trade transparency (TRACE-transparent) had been enforced for all bonds.

\subsubsection{Multiple Regressions on the Impact of Pre-trade Transparent Information}

In addition to comparing bonds by propensity score matching, we ran multiple regressions to examine whether listing on the NYSE (bonds with pre-trade order information) reduces bonds' bid-ask spreads. The dependent variables in the regressions are effective bid-ask spread estimated from equations (23) and (24). We use a similar set of independent variables as in Edwards, Harris and Piwowar (2007), and obtain the same signs and similar significance

levels as their results. Moreover, we also consider other factors that can affect bid-ask spreads and the NYSE listing choice. For example, bond price volatility - which could be related to bond 
spreads and the NYSE listing. If bonds listed on the NYSE happen to have lower volatility, then smaller bid-ask spreads associated with those bonds may arise because of lower volatility but pre-trade transparency. Foreign firms listing equities on U.S. stock exchanges (Miller and Puthenpurackal, 2002) and adopting International Financial Reporting Standards (Gao, 2011) are more likely to choose to list on the U.S. public bond market. Yankee bonds, issued by foreign firms in the U.S. market, can serve as a signal of firms' quality and hence, are more favored by investors. Therefore, we predict that Yankee bonds are cheaper to trade than other bonds, which implies smaller bid-ask spreads. Additionally, bond trading dominated by retail-sized investors ( size $<\$ 100,000)$ may have larger bid-ask spreads than other bonds. In Table 5, we find that in all four regressions, dummy variables for listing on the NYSE have significantly negative impacts on bid-ask spreads, after controlling for firm characteristics, credit risks, retail-sized trading activities and bond-specific characteristics.

From Table 5, we see that the effect of a firm's size on the bid-ask spread is significantly positive. When the bond issuer is a private firm, the bond has higher transaction costs than other bonds. A private firm does not have to agree to disclosure requirements and thus has greater information opaqueness than a publicly listed firm. This opaqueness interferes with investors' ability to evaluate the bond and causes them to incur larger transaction costs. We find no evidence that differences in accounting standards, which may increase the information asymmetry between investors and firms, lead to higher transaction costs. In addition, the estimated results for global bonds are not statistically significant.

To examine whether there is a fixed transaction cost involved in a corporate bond transaction, we include an inverse price in our regressions. Its positive and significant coefficient suggests that corporate bond transactions incur a fixed cost. Standard errors of bond prices are positively and significantly correlated with bonds' bid-ask spreads. This indicates that investors become more cautious and reduce their trading when trading volatile bonds.

Transaction costs are smaller for investment grade bonds than non-investment grade bonds. It is well known that investment grade bonds are more favored by investors than noninvestment grade bonds. Therefore, investment grade bonds cost less to trade than noninvestment grade bonds. Bonds with higher coupon rates, which can be a good indicator for poor credit quality, cost more to trade. Bond age, which represent the number of years being traded in 
the market, are positively related to bid-ask spreads. This is consistent with the "on-the-run" effect faced by corporate bonds. Schultz (2001) finds that lots of trading occurs at issuance and then they are held till maturity. Therefore, a younger bond is more liquid than an older bond, and thus has a smaller bid-ask spread. The relationship between issue size and bid-ask spreads seems to be mixed. Edwards, Harris and Piwowar (2007) provide evidence that large issues are cheaper to trade than small issues. Half of our regression results are consistent with this argument given the negative coefficient estimates of issue size.

Consistent with Edwards, Harris and Piwowar (2007), we find the same evidence on the following variables: variable rate bond (positive), foreign bond (negative), callable bond (negative), and nonstandard accrual (positive). The positive correlation is due to the complexity of bond features which cause additional difficulties to price a bond. The negative coefficient estimates for callable bonds are surprising since the feature makes the bond valuation more difficult. Edwards, Harris and Piwowar (2007) offer a possible explanation that these bonds perform more like short-term bonds than long-term bonds because investors anticipate that many callable bonds will be called. The smaller uncertainties associated with short-term bonds rather than long-term bonds will make valuing a bond easier. When an issuer is in the finance (utility) industry, it costs more for a bond to trade. When an issuer is in default, it is also more expensive to trade.

In addition to the above factors that have been considered in previous studies on bond transaction costs, we consider the effect of retail-sized investors' trading on bid-ask spreads. Biais and Green (2007) show that bond transaction switching from exchange to OTC markets is due to the increasing role of institutional investors in bond trading. To address this concern, we include the percentage of retail-sized trades and trading volume in our regressions, respectively. We find a positive relationship between bid-ask spreads and the proportion of retail-sized trades and trading volume, indicating that small trades occur at a higher transaction cost than trades of institutional investors.

A senior bond has a priority claim in firms' residual assets when the firm faces bankruptcy and thus is more favored by investors. Therefore, a senior bond tends to have a lower transaction cost. Yankee bonds, issued by foreign firms, are significantly cheaper to trade. A separating equilibrium can help to signal the quality of foreign firms who choose to access the 
U.S. capital markets (see Karolyi (2006)). Listing in the U.S capital market can also help widening the firm's investor base (see Merton (1987)). Therefore, Yankee bonds are more favored by investors in the market, which will bring more liquidity to the bonds.

To conclude, our cross-sectional analyses provide evidence that corporate bond transaction costs increase as a bond's credit quality decreases and decrease as the level of a bond's instrument complexity increases. Most importantly, we find that bonds with pre-trade information are cheaper to trade than bonds without pre-trade information, even after controlling for other variables that impact bond transaction costs. Edwards, Harris and Piwowar (2007) also provide evidence that investors probably pay more attention to pre-trade transparent information than to post-trade transparent information. This supports our argument that pre-trade transparent information is at least as important as post-trade transparent information.

\section{Discussion}

Our findings have several important implications.

\subsection{Valuation and Listing Decisions in the Corporate Bond Market}

Since bonds traded in the pre-trade transparent environment have higher liquidity, and since investors value liquidity, the value of NYSE-OTC bonds should be higher than OTC-only bonds. From firms' points of view, having their bonds traded both on the NYSE and in OTC markets should be better than having their bonds traded only in OTC markets. More money will be raised from the former practice. In untabulated results, we do find that the average yield of NYSE-OTC bonds is smaller than the average yield of OTC-only bonds, and the average issue size of NYSE-OTC bonds is larger than the average issue size of OTC-only bonds. In addition, since we model the absence of pre-trade information as Knightian uncertainty, the above implies that changes in Knightian uncertainty could affect firms' listing choices in the corporate bond market. Our findings are closely related to those of Easley and O'Hara (2010b) where they explain how changes in Knightian uncertainty can alter firms' listing decisions in the equity market. 


\subsection{The Policy Implication on OTC Trading}

Our theoretical model also sheds light on recent financial reforms targeting the trading of OTC products. ${ }^{14}$ Though the proposal is intended to deal with netting efficiency and counterparty risks, we show that it has the possibility to boost social welfare as pre-trade transparency is increased. However, we notice that the implementation of the reformation can be challenging, since dealers, who make the OTC market, will oppose the reformation due to shrinking profits.

\subsection{The Empirical Implication on Informed Traders}

In the market microstructure literature, a sophisticated trader, who has more information, faces larger bid-ask spreads, since dealers want to protect themselves against information asymmetry. With this intuition, Pagano and Roell (1996) show that pre-trade transparency decreases bid-ask spreads as information asymmetry is eased. While they emphasize that pretrade transparency enhances dealers' ability to discern informed trading, we emphasize that pretrade transparency refines traders' information set, leading to more bargaining power. This difference leads to different empirical predictions. Given that institutional traders have superior information in trading, Pagano and Roell (1996) predict that institutional-sized trades of pretrade transparent bonds have larger bid-ask spreads because institutional traders' information rents are reduced when more pre-trade information is provided. In contrast, our model predicts the opposite, since the pre-trade information increases institutional traders' bargaining ability, which implies smaller bid-ask spreads for them. To test these predictions, we restrict our controlled experiment to institutional-sized trades. ${ }^{15}$ In Table 6 , we find that the average effective bid-ask spreads are smaller on NYSE-OTC bonds (which are pre-trade transparent) for institutional-sized trades. Though we do not find that the difference is significant for investment grade bonds, we do find that it is statistically and economically significant for non-investment grade bonds. These findings imply that our model dominates the information-based model in explaining the consequence of increasing pre-trade transparency in OTC markets.

\footnotetext{
14 For details, see Dodd-Frank act.

${ }^{15}$ We follow Edwards et al. (2007) to define institutional-sized trades as trades with a size greater than $\$ 100,000$.
} 


\section{Conclusion}

Our paper addresses the question of whether and how increased pre-trade transparency affects OTC trading. Based on the theoretical model and empirical results in the corporate bond market, we conclude that a positive effect on OTC trading can be expected should pre-trade transparency be implemented and enforced. Our contributions are threefold. First, we are the first paper to investigate the relationship between pre-trade transparency and OTC markets' quality. Second, our theoretical model extends the literature on OTC trading by incorporating Knightian uncertainty into the search process. Finally, our empirical results complement studies in the corporate bond market regarding to the pre-trade transparency issue.

We do acknowledge the limitations of our paper. For example, we assume that traders' internal values of the asset are exogenously given. With this assumption, we can emphasize the effect of pre-trade transparency on market trading rather than on the asset value. Given that the goal of our paper is to understand the relationship between pre-trade information and the market quality, we consider this limitation to be relatively inconsequential. 


\section{References}

Acharya, Viral V. and Alberto Bisin, "Counterparty Risk Externality: Centralized versus Overthe-Counter Markets," Working Paper 2010.

Amihud, Yakov and Haim Mendelson, "Dealership Market: Market-Making with Inventory." Journal of Financial Economics, 1980, 8, 31-53.

Bessembinder, Hendrik, Kathleen M. Kahle, William F. Maxwell, and Danielle Xu, "Measuring Abnormal Bond Performance," Review of Financial Studies, 2009, 22, 4219-4258.

Bessembinder, Hendrik, William F. Maxwell and Kumar Venkataraman, "Market Transparency, Liquidity Externalities, and Institutional Trading Costs in Corporate Bonds," Journal of Financial Economics, 2006, 82, 251-288.

Biais, B., and R. Green, 2007, "The Microstructure of the Bond Market in the 20th Century,', working paper, Toulouse University and Carnegie Mellon University.

Bloomfield, Robert and Maureen O'Hara, "Market Transparency: Who Wins and Who Loses?," Review of Financial Studies, 1999, 12, 5-35.

Boehmer, Ekkehart, Gideon Saar, and Lei Yu, "Lifting the Veil: An Analysis of Pre-Trade Transparency at the NYSE," Journal of Finance, 2005, 60, 783-815.

Chakravarty, Sugato and Asani Sarkar, "Trading Costs in Three U.S. Bond Markets," Journal of Fixed Income, June 2003, 13, 39-48.

Chen, L., D. A. Lesmond, and J. Wei, "Corporate Yield Spread and Bond Liquidity." Journal of Finance 2007, 62, 119-149.

Duffie, Darrell, Nicolae Garleanu, and Lasse Heje Pedersen, "Over-the-Counter Markets," Econometrica, 2005, 73, 1815-1847.

Duffie, Darrell, Nicolae Garleanu, and Lasse Heje Pedersen, "Valuation in Over-the-Counter Markets," Review of Financial Studies, 2007, 20, 1865-1900.

Easley, David and Maureen O'Hara, “Ambiguity and Nonparticipation: The Role of Regulation,” Review of Financial Studies, 2009, 22, 1817-1843.

Easley, David and Maureen O’Hara, “Liquidity and Valuation in an Uncertain World,” Journal of Financial Economics, 2010, 97, 1-11.

Easley, David and Maureen O'Hara, “Microstructure and Ambiguity,” Journal of Finance, 2010, $65,1817-1846$. 
Edwards, Amy K., Lawrence E. Harris, and Michael S. Piwowar, "Corporate Bond Market Transaction Costs and Transparency," Journal of Finance, 2007, 62, 1421-1451.20

Ellsberg, Daniel, "Risk, Ambiguity, and the Savage Axioms," Quarterly Journal of Economics, 1961, 75, 643-669.

Eom, Kyong Shik, Jinho Ok and Jong-Ho Park, "Pre-trade Transparency and Market Quality," Journal of Financial Markets, 2007, 10, 319-341.

Flood, Mark D., Ronald Huisman, Kees G. Koedijk, and Ronald J. Mahieu, "Quote Disclosure and Price Discovery in Multiple-Dealer Financial Markets," Review of Financial Studies, 1999, 12, 37-59.

Gao, Yu, "The Sarbanes-Oxley Act and the Choice of Bond Market by Foreign Firms." Journal of Accounting Research, 2011,49 (4), 933-968.

Garman, Mark B., "Market Microstructure," Journal of Financial Economics, 1976, 3, 257-275.

Goldstein, Michael, Edith Hotchkiss, and Erik Sirri, "Transparency and Liquidity: A Controlled Experiment on Corporate Bonds," Review of Financial Studies, 2007, 20, 235-273.

Green, Richard C., Burton Hollifield, and Norman Schürhoff, "Financial Intermediation and the Costs of Trading in an Opaque Market," Review of Financial Studies, 2007, 20, 275-314.

Hansen, Lars Peter and Thomas J. Sargent, “Acknowledging Misspecification in Macroeconomic Theory," Review of Economic Dynamics, 2001, 4, 519-535.

Hong, Gwangheon and Arthur Warga, "An Empirical Study of Bond Market Transactions," Financial Analysts Journal, 2000, 56, 32-46.

Karolyi, G. A., "The World of Cross-Listings and Cross-Listings of the World: Challenging Conventional Wisdom.” Review of Finance 2006; 10: 99-152.

Lagos, Ricardo and Guillaume Rocheteau, "Liquidity in Asset Markets with Search Frictions," Econometrica, 2009, 77, 403-426.

Madhavan, Ananth, David Porter, and Daniel Weaver, "Should Securities Markets Be Transparent?" Journal of Financial Markets, 2005, 8, 265-287.

Merton, Robert C., "A Simple Model of Capital Market Equilibrium with Incomplete Information," Journal of Finance, 1987, 42, 483-510.

Miller, Darius P., and John J. Puthenpurackal, "The Costs, Determinants, and Wealth Effects of International Capital Raising,” Journal of Financial Intermediation, 2002, 11, 455-485. 
Nishimura, Kiyohiko G. and Hiroyuki Ozaki, "Search and Knightian Uncertainty," Journal of Economic Theory, 2004, 119 (2), 299-333.

O’Hara, Maureen, “Optimal Microstructures,” European Financial Management, 2007, 13, 825832.

Pagano, Marco and Ailsa Roell, "Transparency and Liquidity: A Comparison of Auction and Dealer Markets with Informed Trading," Journal of Finance, 1996, 51, 579-611.

Rust, John and George Hall, "Middlemen versus Market Makers: A Theory of Competitive Exchange," Journal of Political Economy, 2003, 111, 353-403.

Schmeidler, David, "Subjective Probability and Expected Utility without Additivity," Econometrica, 1989, 57, 571-587.

Schultz, Paul, "Corporate Bond Trading Costs: A Peek Behind the Curtain," Journal of Finance, 2001, 56, 677-698.

Spulber, Daniel F., "Market Making by Price-Setting Firms," Review of Economic Studies, 1996, $63,559-580$.

Vayanos, Dimitri and Tan Wang, "Search and Endogenous Concentration of Liquidity in Asset Markets," Journal of Economic Theory, 2007, 136, 66-104.

Zhu, Haoxiang, "Finding a Good Price in Opaque Over-the-Counter Markets," Working Paper 2011. 


\section{Appendix}

Proof of Proposition 1

Proof:

Let's denote $D(a)=\sum_{t} \beta^{t} D_{t}(a)$ and $S(b)=\sum_{t} \beta^{t} S_{t}(b)$. Given that $D_{t}(a)$ is continuous and decreasing function on $[\underline{a}, \bar{a}]$, it is easy to see that $D(a)$ is continuous and decreasing on $[\underline{a}, \bar{a}]$. We note that, from the value function of the buyers

$$
V^{B}(a)=\max \left\{0, v^{B}-a, \beta \int V^{B}(\hat{a}) d \theta_{a}\right\}
$$

$\underline{a}=\underline{v}^{B}$ and $\bar{a}=r^{B}(1)$. Similarly, we have $S(b)$ continuous and increasing on $[\underline{b}, \bar{b}]$, in which $\underline{b}=r^{S}(0)$ and $\bar{b}=\bar{v}^{S}$. As $D_{t}(a)=S_{t}(b)$, we have $D(a)=S(b)$. Then, we define the inverse functions $A(q)$ and $B(q)$ mapping from $q$ to prices.

From the inverse function theorem, we have

$$
\begin{gathered}
A^{\prime}(q)=\left(\frac{\partial D}{\partial a}\right)^{-1}=\left(-\frac{1-\beta+F_{a}(a)(1-\epsilon) \beta}{N(1-\beta)\left(1-\beta\left(1-F_{a}(a)\right)\right)}\right)^{-1}, \\
B^{\prime}(q)=\left(\frac{\partial S}{\partial b}\right)^{-1}=\left(\frac{1-\beta+\left(1-F_{b}(b)\right)(1-\epsilon) \beta}{N(1-\beta)\left(1-\beta F_{b}(b)\right)}\right)^{-1} .
\end{gathered}
$$

As $a(k)$ increases in $k$ and $b(k)$ decreases in $k$, we have

$$
\begin{array}{r}
F_{a}(a)=P_{a}[\hat{a}<a]=P_{k}[\hat{k}<k]=\frac{k-\underline{k}}{k^{*}-\underline{k}}, \\
1-F_{b}(b)=P_{b}[\hat{b}<b]=P_{k}[\hat{k}<k]=\frac{k-\underline{k}}{k^{*}-\underline{k}},
\end{array}
$$

where $k^{*}$ is the marginal dealer whose profit margin and trading volume are zeros. Thus, the total mass of dealer $N$ equals to $k^{*}-\underline{k}$.

Plugging $F_{a}(a)$ and $F_{b}(b)$ into $A^{\prime}(q)$ and $B^{\prime}(q)$ respectively, we obtain

$$
A^{\prime}(q)=-B^{\prime}(q)=\left(-\frac{1-\beta+\frac{k-\underline{k}}{k^{*}-\underline{k}}(1-\epsilon) \beta}{N(1-\beta)\left(1-\frac{\beta\left(k^{*}-k\right)}{k^{*}-\underline{k}}\right)}\right)^{-1} .
$$

For the dealer with transaction cost $k$, he chooses $q$ to maximize the expected profit $(A(q)-B(q)-k) q$. The optimality condition implies,

$$
A(q)-B(q)-k=\left(B^{\prime}(q)-A^{\prime}(q)\right) q
$$

Thus, we obtain 


$$
A(q(k))-B(q(k))-k=\frac{2\left(k^{*}-\underline{k}\right)(1-\beta)\left(1-\frac{\beta\left(k^{*}-k\right)}{k^{*}-\underline{k}}\right) q(k)}{1-\beta+\frac{k-\underline{k}}{k^{*}-\underline{k}}(1-\epsilon) \beta} .
$$

Substituting $q(k)=D(a(k))$ into equation (A8), we get

$$
a(k)-b(k)-k=\frac{2\left(1-\frac{\beta\left(k^{*}-k\right)}{k^{*}-\underline{k}}\right)}{1-\beta+\frac{k-\underline{k}}{k^{*}-\underline{k}}(1-\epsilon) \beta} \int_{a(k)}^{r^{B}(1)} \frac{1-\beta+F_{a}\left(r^{B}\right)(1-\epsilon) \beta}{1-\beta\left(1-F_{a}\left(r^{B}\right)\right)} d r^{B} .
$$

Since, for any $k, D(a(k))=S(b(k))$, it implies that $\frac{\partial D}{\partial k}=\frac{\partial S}{\partial k}$. And since $A^{\prime}(q)=-B^{\prime}(q)$, we have $\frac{\partial a}{\partial k}=-\frac{\partial b}{\partial k}$. Thus,

$$
a(k)+b(k)=C,
$$

in which $C$ represents a constant.

From the buyer's reservation value, we have

$$
1=r^{B}(1)+\frac{\beta(1-\epsilon)}{1-\beta} \int_{\underline{a}}^{r^{B}(1)} P_{a}[a<\hat{a}] d \hat{a}=r^{B}(1)+\frac{\beta(1-\epsilon)}{1-\beta} \int_{\underline{k}}^{k^{*}} \frac{k-\underline{k}}{k^{*}-\underline{k}} a^{\prime}(k) d k,
$$

where the second equality is obtained by performing a change of variables.

Likewise, we have

$$
0=r^{S}(0)-\frac{\beta(1-\epsilon)}{1-\beta} \int_{r^{S}(0)}^{\bar{b}} P_{b}[b>\hat{b}] d \hat{b}=r^{S}(0)+\frac{\beta(1-\epsilon)}{1-\beta} \int_{\underline{k}}^{k^{*}} \frac{(k-\underline{k})}{k^{*}-\underline{k}} b^{\prime}(k) d k .
$$

From the above, it is obvious that $1=r^{B}(1)+r^{S}(0)$. Since $a\left(k^{*}\right)=\bar{a}=r^{B}(1)$ and $b\left(k^{*}\right)=\underline{b}=r^{S}(0)$, we have $a\left(k^{*}\right)+b\left(k^{*}\right)=1$. This implies $C=1$, and hence,

$$
b(k)=1-a(k) .
$$

Plugging the equation (A13) into the optimality condition (equation (A8)) and differentiating with respect to $k$, we arrive at the following differential equation

$$
a^{\prime}(k)-\frac{a(k)(\beta X(k))}{2\left(k^{*}-\underline{k}\right)}=\frac{1}{4}-\frac{1+k}{4} \frac{\beta X(k)}{k^{*}-\underline{k}},
$$

where

$$
X(k)=\frac{1}{1-\frac{\beta\left(k^{*}-k\right)}{k^{*}-\underline{k}}}-\frac{1-\epsilon}{1-\beta+\frac{k-\underline{k}}{k^{*}-\underline{k}}(1-\epsilon) \beta} .
$$

The solution for the above differential equation is

$$
a(k)=e^{\int_{z}^{k^{*}}-Y(z) d z}\left(\frac{k^{*}+1}{2}+\int_{k}^{k^{*}}\left(-\frac{1}{4}+\frac{1+z}{2} Y(z)\right) e^{\int_{z}^{k^{*}} Y(u) d u} d z\right),
$$

where 


$$
Y(z)=\frac{\beta X(z)}{2\left(k^{*}-\underline{k}\right)} .
$$

Thus, equation (A16) determines the equilibrium asks. And the equilibrium bids equal to $1-a$.

To determine the equilibrium $k^{*}$, we apply $k^{*}=a\left(k^{*}\right)-b\left(k^{*}\right)$ to the buyer's reservation value $r^{B}(1)$ and get

$$
1=\frac{k^{*}+1}{2}+\frac{\beta(1-\epsilon)}{1-\beta}\left(\frac{k^{*}+1}{2}-\frac{1}{k^{*}-\underline{k}} \int_{\underline{k}}^{k^{*}} a(k) d k\right) .
$$

Q.E.D. 
Table 1: Sample Composition

This table describes the composition of the final sample. The filtration applied rules out bonds that are: (i) putable; (ii) with abnormal prices (less than $\$ 10$ or greater than $\$ 200$ ); (iii) subsequently corrected; and (iv) affected by price reversions. We further require bonds to have at least one buy and one sell within a day is adopted. Lastly, all but NYSE listed bonds are discarded.

\begin{tabular}{|c|c|c|c|c|c|c|}
\hline & $\begin{array}{l}\text { \# of } \\
\text { Bonds }\end{array}$ & \# of Trades & $\operatorname{Size}(\$ s)$ & Yield(\%) & Coupon $(\%)$ & Dollar Volume (Billions) \\
\hline $\begin{array}{l}\text { Data downloaded from } \\
\text { TRACE(Starting from Nov 1, } 2008 \\
\text { to March 31, 2011) }\end{array}$ & 40,977 & $26,658,403$ & $285,916.96$ & 8.98 & N.A. & $7,621.94$ \\
\hline After filtering conditions: & 25,884 & $24,958,872$ & $276,633.09$ & 8.04 & 5.90 & $6,904.32$ \\
\hline Sell & 25,146 & $9,058,715$ & $279,239.83$ & 6.90 & 5.90 & $2,529.54$ \\
\hline Inter-dealer & 25,167 & $10,019,697$ & $206,389.84$ & 8.32 & 5.92 & $2,067.92$ \\
\hline Buy & 24,263 & $5,880,460$ & $392,306.06$ & 9.35 & 5.85 & $2,306.86$ \\
\hline \multicolumn{7}{|l|}{$\begin{array}{l}\text { Sample(only buy and sell plus } \\
\text { NYSE) }\end{array}$} \\
\hline OTC & 17,542 & $6,704,865$ & $315,223.74$ & 8.99 & 5.81 & $2,113.52$ \\
\hline NYSE & 4,247 & $3,771,301$ & $424,736.78$ & 5.91 & 6.04 & $1,601.74$ \\
\hline Sell & 21,789 & $6,353,230$ & $301,790.80$ & 6.90 & 5.90 & $1,917.33$ \\
\hline Buy & 21,789 & $4,122,936$ & $436,096.45$ & 9.37 & 5.88 & $1,797.92$ \\
\hline
\end{tabular}




\begin{tabular}{|c|c|c|c|c|c|c|}
\hline & \# of Bonds & \# of Trades & Size $(\$ s)$ & Yield(\%) & Coupon(\%) & Dollar Volume (Billions) \\
\hline $\begin{array}{l}\text { Data downloaded from TRACE(Starting } \\
\text { from Nov 1, } 2008 \text { to March 31, 2011) }\end{array}$ & 40,977 & $26,658,403$ & $285,916.96$ & 8.98 & N.A. & $7,621.94$ \\
\hline After filtering conditions: & 25,884 & $24,958,872$ & $276,633.09$ & 8.04 & 5.90 & $6,904.32$ \\
\hline Sell & 25,146 & $9,058,715$ & $279,239.83$ & 6.90 & 5.90 & $2,529.54$ \\
\hline Inter-dealer & 25,167 & $10,019,697$ & $206,389.84$ & 8.32 & 5.92 & $2,067.92$ \\
\hline Buy & 24,263 & $5,880,460$ & $392,306.06$ & 9.35 & 5.85 & $2,306.86$ \\
\hline \multicolumn{7}{|l|}{ Sample(only buy and sell plus NYSE) } \\
\hline OTC & 17,542 & $6,704,865$ & $315,223.74$ & 8.99 & 5.81 & $2,113.52$ \\
\hline NYSE & 4,247 & $3,771,301$ & $424,736.78$ & 5.91 & 6.04 & $1,601.74$ \\
\hline Sell & 21,789 & $6,353,230$ & $301,790.80$ & 6.90 & 5.90 & $1,917.33$ \\
\hline Buy & 21,789 & $4,122,936$ & $436,096.45$ & 9.37 & 5.88 & $1,797.92$ \\
\hline
\end{tabular}

Table 2: Effective Bid-ask Spreads Matched by the Same Issuer

The sample period is from November 1, 2008 to March 31, 2011. This table presents the differences of bid-ask spreads between OTConly bonds with OTC-NYSE bonds, at the issuer level across ratings. The bid-ask spread is estimated as the time series average of its traded bid-ask spreads in a one-day window. For each bond, the traded bid-ask spread is the difference between the average daily selling price and average daily buying price divided by their sum. Superior bonds include bonds that have a moody rating of Aaa, Aa1, 
Aa and Aa2 during the sample period. Other investment bonds consist of bonds that have a rating between Baa3 and Aa3. Bonds rated as Baa3 belong to non-investment bonds category. tt-test (Wilcoxon) is used to test the difference of mean (median) bid-ask spreads between the two groups of bonds.

\begin{tabular}{|c|c|c|c|c|c|c|c|c|c|c|c|c|c|c|}
\hline & \multicolumn{6}{|c|}{ OTC-only } & \multicolumn{6}{|c|}{ OTC-NYSE } & \multicolumn{2}{|c|}{ Difference } \\
\hline & \# of bonds & Mean(Basis Points) & t Value & Std Dev *100 & Coupon $(\%)$ & Age(Years) & \# of bonds & Mean(Basis Points) & t Value & Std Dev *100 & Coupon $(\%)$ & Age(Years) & tt-test & Wilcoxn \\
\hline Total & 9,587 & 106 & 110.05 & 0.94 & 4.93 & 4.72 & 3,082 & 81 & 75.85 & 0.59 & 5.90 & 4.81 & 0.00 & 0.00 \\
\hline Superior Bonds (Aa2 and up) & 643 & 78 & 24.89 & 0.80 & 3.26 & 3.16 & 124 & 47 & 12.35 & 0.42 & 4.21 & 3.49 & 0.00 & 0.00 \\
\hline Other Investment Bonds (Aa3-Baa3) & 6,120 & 100 & 96.77 & 0.81 & 5.02 & 4.83 & 2,107 & 79 & 66.19 & 0.55 & 5.70 & 4.56 & 0.00 & 0.00 \\
\hline Non-investment Bonds & 1,856 & 132 & 41.54 & 1.37 & 5.35 & 4.94 & 538 & 80 & 23.63 & 0.79 & 7.40 & 5.53 & 0.00 & 0.00 \\
\hline
\end{tabular}


Table 3: Variable Definitions

\begin{tabular}{|c|c|}
\hline Variable & Description \\
\hline \multicolumn{2}{|l|}{ Firm Characteristics } \\
\hline Total assets (log millions) & Natural logarithm of total assets in the fiscal year prior to the bond issue \\
\hline Long-term Debt/Total assets & Ratio of long-term debt over total asset in the fiscal year prior to the bond issue \\
\hline Issuers' equity is private & Binary variable equal to 1 when the issuer is a private firm \\
\hline Firms' accounting standard-IFRS & $\begin{array}{l}\text { Binary variable equal to } 1 \text { when the accounting standard that a company uses in presenting its financial } \\
\text { statements is International Financial Reporting Standards }\end{array}$ \\
\hline Firms' accounting standard-Domestic & $\begin{array}{l}\text { Binary variable equal to } 1 \text { when the accounting standard that a company uses in presenting its financial } \\
\text { statements is Domestic }\end{array}$ \\
\hline Firms' accounting standard-GAAP & $\begin{array}{l}\text { Binary variable equal to } 1 \text { when the accounting standard that a company uses in presenting its financial } \\
\text { statements is Generally Accepted Accounting Principles }\end{array}$ \\
\hline \multicolumn{2}{|r|}{ 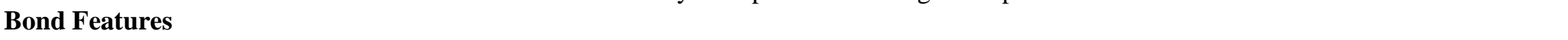 } \\
\hline Inverse average price & Inverse value of mean bond prices across the sample period \\
\hline Bond prices S.D. & Standard deviation of bond prices \\
\hline Investment bond & Binary variable equal to 1 when the bond belongs to Investment Category \\
\hline Rating is Baa & Binary variable equal to 1 when the bond's rating is Baa \\
\hline Rating is $\mathrm{Ba}, \mathrm{Ba} 2, \mathrm{~B}$ or $\mathrm{B} 2$ & Binary variable equal to 1 when the bond's rating is $\mathrm{Ba}, \mathrm{Ba} 2, \mathrm{~B}$ or $\mathrm{B} 2$ \\
\hline Rating is $\mathrm{C}$ and Below & Binary variable equal to 1 when the bond's rating is $\mathrm{C}$ and Below \\
\hline Coupon rate & The current applicable annual interest rate divided by 100. \\
\hline Age (sq. root) & Square root of the number of years since the bond is issued \\
\hline Years to maturity (sq. root) & Square root of the number of years before the bond is expired \\
\hline Issue size (sq. root of millions) & Square root of the par value of debt initially issued. \\
\hline Global Bond & Binary variable equal to 1 when the issue is offered globally \\
\hline Yankee Bond & $\begin{array}{l}\text { Binary variable equal to } 1 \text { when the bond is issued by a foreign issuer, but is registered with the SEC and } \\
\text { is payable in dollars. }\end{array}$ \\
\hline Foreign bond & Binary variable equal to 1 when the issue is denominated in a foreign currency. \\
\hline Senior bond & Binary variable equal to 1 when the security is a senior issue of the issuer. \\
\hline
\end{tabular}




\section{Rule144a bond}

Callable bond

Variable rate bond

Nonstandard payment

Nonstandard accrual

Issuer is in finance industry

Issuer is a utility

Issuer is in default

$\%$ of retail-sized trades

$\%$ of retail-sized trades' volume

Listed on the NYSE
Binary variable equal to 1 when the issue is a private placement exempt from registration under SEC Rule 144a.

Binary variable equal to 1 when the bond is redeemable under certain conditions

Binary variable equal to 1 when the coupon type for the issue is variable

Binary variable equal to 1 when the number of interest payments per year is not equal to 2

Binary variable equal to 1 when daily basis used for calculating the interest paid during each interest period is not 30/360.

Binary variable equal to 1 when the issuer belongs to the finance industry

Binary variable equal to 1 when the issuer belongs to the utility industry

Binary variable equal to 1 when the issuer is in default of the terms of this issue.

Ratio of the number of retail-sized trades $(<\$ 100,000)$ relative to total number of trades

Ratio of the volume of retail-sized trades $(<\$ 100,000)$ relative to total volume of trades

Binary variable equal to 1 when the bond is listed on the NYSE 
Table 4: Effective Bid-ask Spreads Differences by Propensity Score Matching

\begin{tabular}{|c|c|c|c|c|}
\hline \multicolumn{5}{|c|}{ Panel A: Dependent Variable: Listed on NYSE YES/NO } \\
\hline & Coefficient & P-value & Coefficient & P-value \\
\hline Intercept & 3.74 & $(0.00)$ & 1.77 & $(0.02)$ \\
\hline Total assets (log millions) & & & 0.08 & $(0.00)$ \\
\hline Long-term Debt/Total assets & & & -0.13 & $(0.27)$ \\
\hline Issuers' equity is private & & & -0.82 & $(0.08)$ \\
\hline Firms' accounting standard-IFRS & & & -0.42 & $(0.57)$ \\
\hline Firms' accounting standard-Domestic & & & -0.21 & $(0.78)$ \\
\hline Firms' accounting standard-GAAP & & & 0.52 & $(0.48)$ \\
\hline Coupon rate & -11.00 & $(0.00)$ & -15.80 & $(0.00)$ \\
\hline Issue size (log millions) & -0.49 & $(0.00)$ & -0.05 & $(0.00)$ \\
\hline Moody's bond rating & 0.07 & $(0.00)$ & 0.06 & $(0.00)$ \\
\hline Years to maturity & -0.01 & $(0.00)$ & -0.01 & $(0.00)$ \\
\hline Global bond & -0.18 & $(0.00)$ & -0.39 & $(0.00)$ \\
\hline Yankee bond & -0.39 & $(0.00)$ & -0.57 & $(0.00)$ \\
\hline Foreign bond & -0.50 & $(0.74)$ & -0.25 & $(0.87)$ \\
\hline Senior bond & 0.71 & $(0.00)$ & 0.82 & $(0.00)$ \\
\hline Rule144a bond & 2.91 & $(0.00)$ & 2.12 & $(0.01)$ \\
\hline Callable bond & -0.21 & $(0.00)$ & -0.21 & $(0.00)$ \\
\hline Variable rate bond & 2.69 & $(0.00)$ & 2.60 & $(0.00)$ \\
\hline Nonstandard payment & -0.12 & $(0.09)$ & -0.53 & $(0.00)$ \\
\hline Nonstandard accrual & 0.16 & $(0.60)$ & 0.23 & $(0.70)$ \\
\hline Issuer is in finance industry & -0.07 & $(0.20)$ & -0.11 & $(0.07)$ \\
\hline Issuer is a utility & -0.21 & $(0.00)$ & -0.31 & $(0.00)$ \\
\hline Issuer is in default & 2.09 & $(0.00)$ & 2.19 & $(0.00)$ \\
\hline Pseudo R-square & \multicolumn{2}{|c|}{0.24} & \multicolumn{2}{|c|}{0.26} \\
\hline \# of Bonds & \multicolumn{2}{|c|}{20,981} & \multicolumn{2}{|c|}{17,963} \\
\hline \multicolumn{5}{|c|}{ Panel B: Propensity Scoring Matched Bid-ask Spread Difference } \\
\hline & $\begin{array}{c}\text { OTC- } \\
\text { only }\end{array}$ & $\begin{array}{c}\text { OTC- } \\
\text { NYSE }\end{array}$ & $\begin{array}{c}\text { OTC- } \\
\text { only }\end{array}$ & $\begin{array}{l}\text { OTC- } \\
\text { NYSE }\end{array}$ \\
\hline Spread-Mean (bps) & 83 & 77 & 88 & 77 \\
\hline S.D. $* 10000$ & 74 & 59 & 65 & 57 \\
\hline tt-test for differences & \multicolumn{2}{|c|}{0.00} & \multicolumn{2}{|c|}{0.00} \\
\hline Wilcoxon-test for differences & \multicolumn{2}{|c|}{0.00} & \multicolumn{2}{|c|}{0.00} \\
\hline \# of Bonds & \multicolumn{2}{|c|}{4,206} & \multicolumn{2}{|c|}{3,859} \\
\hline
\end{tabular}


Table 5: Cross-sectional Determinants of Effective Bid-ask Spreads

This table reports regression coefficients in which estimated bid-ask spreads are related to various bond characteristics.

\begin{tabular}{|c|c|c|c|c|c|c|c|c|}
\hline & Coefficient*1000 & $\mathrm{P}$-value & Coefficient*1000 & P-value & Coefficient*1000 & P-value & Coefficient*1000 & P-value \\
\hline Intercept & -4.82 & $(0.02)$ & -4.96 & $(0.01)$ & -4.38 & $(0.03)$ & -4.56 & $(0.02)$ \\
\hline Total assets (log millions) & 0.13 & $(0.00)$ & 0.08 & $(0.01)$ & 0.07 & $(0.03)$ & 0.02 & $(0.45)$ \\
\hline Issuers' equity is private & 1.46 & $(0.23)$ & 1.57 & $(0.19)$ & 1.01 & $(0.40)$ & 1.15 & $(0.34)$ \\
\hline Firms' accounting standard-IFRS & 0.73 & $(0.72)$ & 0.49 & $(0.80)$ & 1.24 & $(0.54)$ & 1.00 & $(0.61)$ \\
\hline Firms' accounting standard-Domestic & 0.07 & $(0.97)$ & -0.11 & $(0.96)$ & 0.51 & $(0.79)$ & 0.33 & $(0.87)$ \\
\hline Firms' accounting standard-GAAP & 0.92 & $(0.64)$ & 0.92 & $(0.64)$ & 1.62 & $(0.42)$ & 1.60 & $(0.42)$ \\
\hline Inverse average price & 23.93 & $(0.00)$ & 27.21 & $(0.00)$ & 61.28 & $(0.00)$ & 63.35 & $(0.00)$ \\
\hline Bond prices S.D. & 0.45 & $(0.00)$ & 0.45 & $(0.00)$ & 0.49 & $(0.00)$ & 0.49 & $(0.00)$ \\
\hline Investment bond & -1.01 & $(0.00)$ & -1.03 & $(0.00)$ & & & & \\
\hline Rating is Baa & & & & & -0.29 & $(0.15)$ & -0.34 & $(0.09)$ \\
\hline Rating is $\mathrm{Ba}, \mathrm{Ba} 2, \mathrm{~B}$ or $\mathrm{B} 2$ & & & & & -0.29 & $(0.51)$ & 0.02 & $(0.96)$ \\
\hline Rating is $\mathrm{C}$ and Below & & & & & -3.07 & $(0.00)$ & -2.94 & $(0.00)$ \\
\hline Coupon rate & 35.69 & $(0.00)$ & 33.09 & $(0.00)$ & 39.13 & $(0.00)$ & 36.58 & $(0.00)$ \\
\hline Age (sq. root) & 0.22 & $(0.00)$ & 0.30 & $(0.00)$ & -0.08 & $(0.25)$ & 0.00 & $(0.99)$ \\
\hline Years to maturity (sq. root) & 0.79 & $(0.00)$ & 0.85 & $(0.00)$ & 0.72 & $(0.00)$ & 0.78 & $(0.00)$ \\
\hline Issue size (sq. root of millions) & 0.03 & $(0.00)$ & -0.04 & $(0.00)$ & 0.01 & $(0.03)$ & -0.05 & $(0.00)$ \\
\hline Global bond & 0.36 & $(0.02)$ & 0.07 & $(0.67)$ & 0.05 & $(0.76)$ & -0.22 & $(0.17)$ \\
\hline Yankee bond & -3.51 & $(0.00)$ & -3.36 & $(0.00)$ & -2.53 & $(0.00)$ & -2.43 & $(0.00)$ \\
\hline Foreign bond & -7.83 & $(0.02)$ & -6.08 & $(0.07)$ & -8.03 & $(0.02)$ & -6.36 & $(0.06)$ \\
\hline Senior bond & -1.23 & $(0.00)$ & -1.03 & $(0.00)$ & -1.18 & $(0.00)$ & -0.99 & $(0.00)$ \\
\hline Rule144a bond & -0.05 & $(0.97)$ & 1.24 & $(0.37)$ & 0.20 & $(0.89)$ & 1.41 & $(0.31)$ \\
\hline Callable bond & -0.37 & $(0.00)$ & -0.40 & $(0.00)$ & -0.54 & $(0.00)$ & -0.56 & $(0.00)$ \\
\hline Variable rate bond & 1.75 & $(0.00)$ & 1.52 & $(0.00)$ & 1.83 & $(0.00)$ & 1.62 & $(0.00)$ \\
\hline Nonstandard payment & -1.81 & $(0.00)$ & -1.57 & $(0.00)$ & -1.38 & $(0.00)$ & -1.16 & $(0.00)$ \\
\hline Nonstandard accrual & 0.64 & $(0.04)$ & 1.88 & $(0.00)$ & 0.06 & $(0.85)$ & 1.26 & $(0.00)$ \\
\hline Issuer is in finance industry & 1.14 & $(0.00)$ & 1.12 & $(0.00)$ & 0.85 & $(0.00)$ & 0.84 & $(0.00)$ \\
\hline Issuer is a utility & 0.77 & $(0.00)$ & 0.80 & $(0.00)$ & 0.41 & $(0.05)$ & 0.45 & $(0.03)$ \\
\hline
\end{tabular}




\begin{tabular}{|c|c|c|c|c|c|c|c|c|}
\hline Issuer is in default & 3.60 & $(0.00)$ & 3.62 & $(0.00)$ & 5.59 & $(0.00)$ & 5.55 & $(0.00)$ \\
\hline$\%$ of retail-sized trades & & & 10.28 & $(0.00)$ & & & 9.71 & $(0.00)$ \\
\hline$\%$ of retail-sized trades' volume & 9.78 & $(0.00)$ & & & 9.17 & $(0.00)$ & & \\
\hline Listed on the NYSE & -0.26 & $(0.03)$ & -0.24 & $(0.05)$ & -0.49 & $(0.00)$ & -0.46 & $(0.00)$ \\
\hline Adj. R-square & \multicolumn{2}{|c|}{0.43} & & & \multicolumn{2}{|c|}{0.44} & \multicolumn{2}{|c|}{0.45} \\
\hline \# of Bonds & & & & & & & & \\
\hline
\end{tabular}

Table 6: Effective Bid-ask Spreads of Institutional-Sized trades

This table reports results of only institutional-sized trades. Total sample includes all bonds and sub sample includes all bonds matched by the same issuer.

\begin{tabular}{|c|c|c|c|c|c|c|c|c|c|c|c|}
\hline & & \multicolumn{4}{|c|}{ OTC } & \multicolumn{4}{|c|}{ NYSE-OTC } & \multicolumn{2}{|c|}{ Difference } \\
\hline & & $\#$ of bonds & Mean(Basis Points) & $\mathrm{t}$ Value & Std Dev*100 & \# of bonds & Mean(Basis Points) & $\mathrm{t}$ Value & Std Dev*100 & tt-test & Wilcoxn \\
\hline \multirow{3}{*}{$\begin{array}{c}\text { Total } \\
\text { Sample }\end{array}$} & Total & 9,933 & 45 & 60.01 & 0.75 & 3,662 & 37 & 51.45 & 0.43 & $<.0001$ & 0.1838 \\
\hline & Investment Bonds & 5,858 & 39 & 50.87 & 0.58 & 2,763 & 38 & 44.06 & 0.46 & 0.5792 & $<.0001$ \\
\hline & Non-investment Bonds & 4,075 & 54 & 37.15 & 0.93 & 899 & 33 & 27.79 & 0.35 & $<.0001$ & $<.0001$ \\
\hline \multirow{3}{*}{$\begin{array}{c}\text { Sub } \\
\text { Sample }\end{array}$} & Total & 4,464 & 45 & 50.90 & 0.59 & 2,527 & 39 & 41.22 & 0.47 & $<.0001$ & 0.0004 \\
\hline & Investment Bonds & 3,282 & 41 & 43.92 & 0.53 & 2,016 & 40 & 36.15 & 0.50 & 0.4357 & 0.8133 \\
\hline & Non-investment Bonds & 1,182 & 57 & 27.23 & 0.72 & 511 & 34 & 21.11 & 0.37 & $<.0001$ & $<.0001$ \\
\hline
\end{tabular}


Figure 1: Comparative statics of the average bid-ask spread in the search equilibrium of Proposition 1 with respect to $\epsilon$. The parameters are $\beta=0.9$ and $\underline{k}=0.005$.

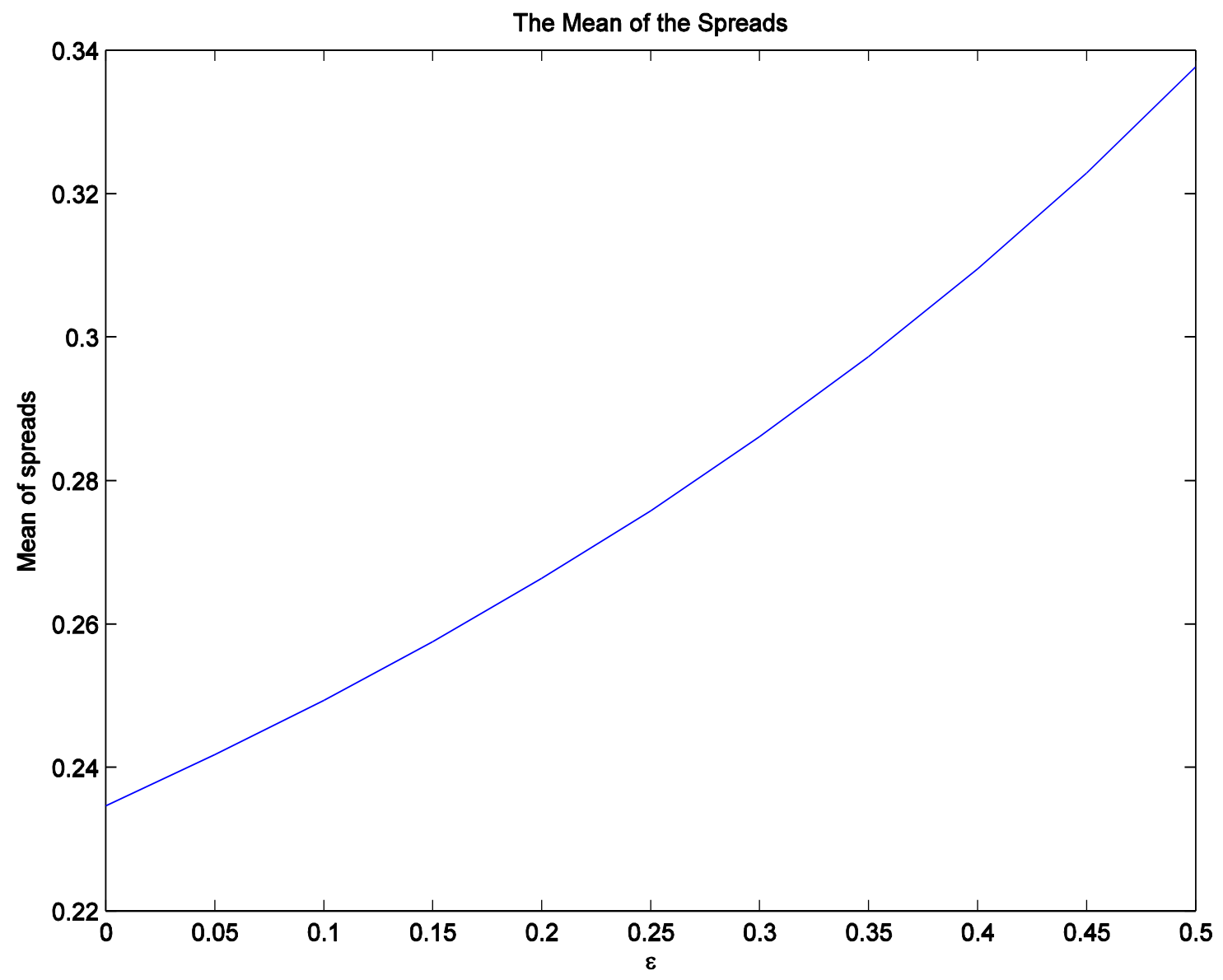


Figure 2: Comparative statics of the demographics in the equilibrium of Proposition 1 with respect to $\epsilon$. The parameters are the same as in Figure 1. The left panel plots the total mass of dealers in the equilibrium, and the right panel plots the total mass of traders in the equilibrium.
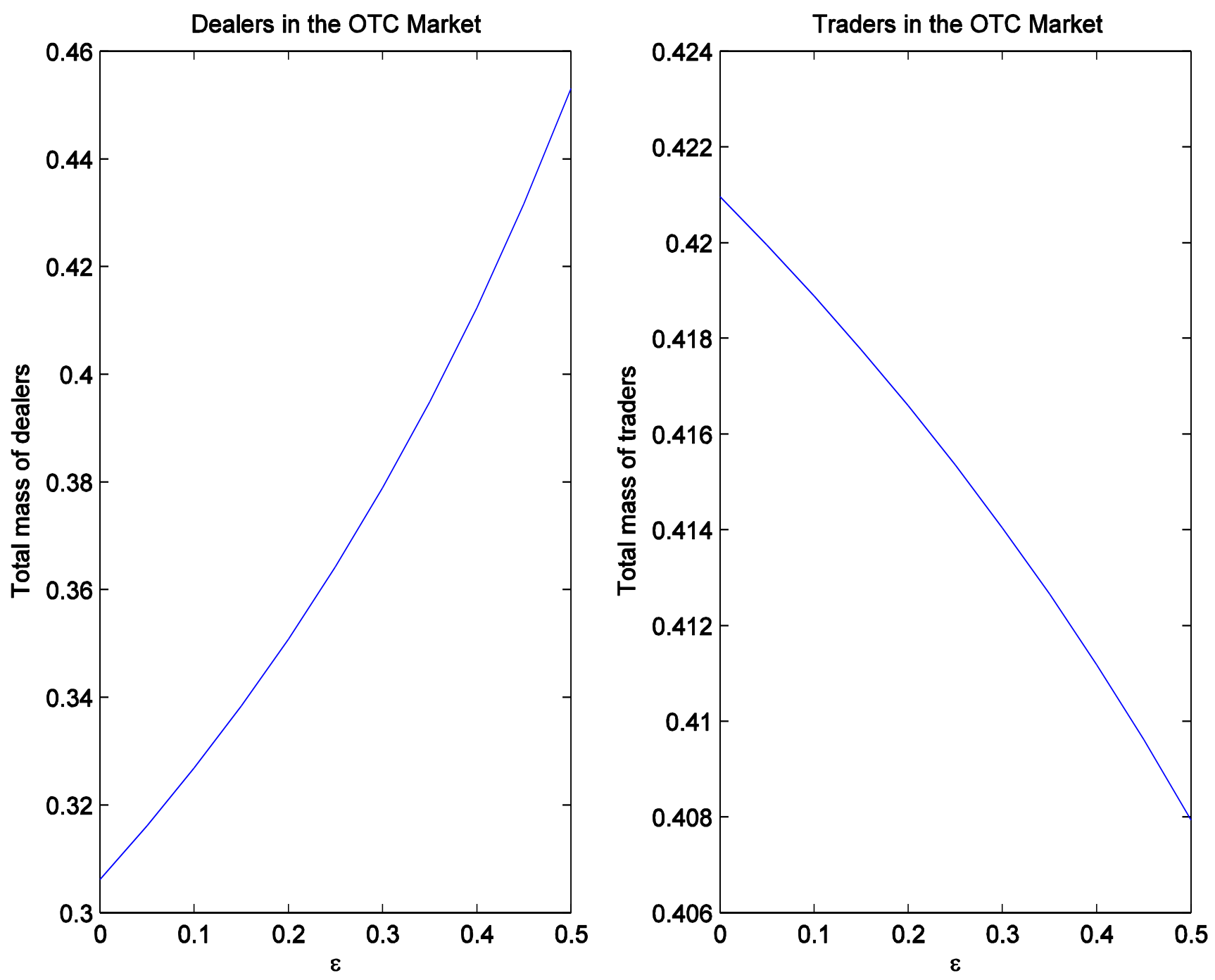
Figure 3: The comparison of the equilibrium asks between a less transparent OTC market $(\epsilon=0.5)$ and a completely transparent OTC market $(\epsilon=0)$. Solid lines show the asks when the OTC market is less transparent, and dashed lines show the asks when the OTC market is completely transparent. The left panel plots the equilibrium asks, and the right panel plots the empirical cumulative density functions of the asks.
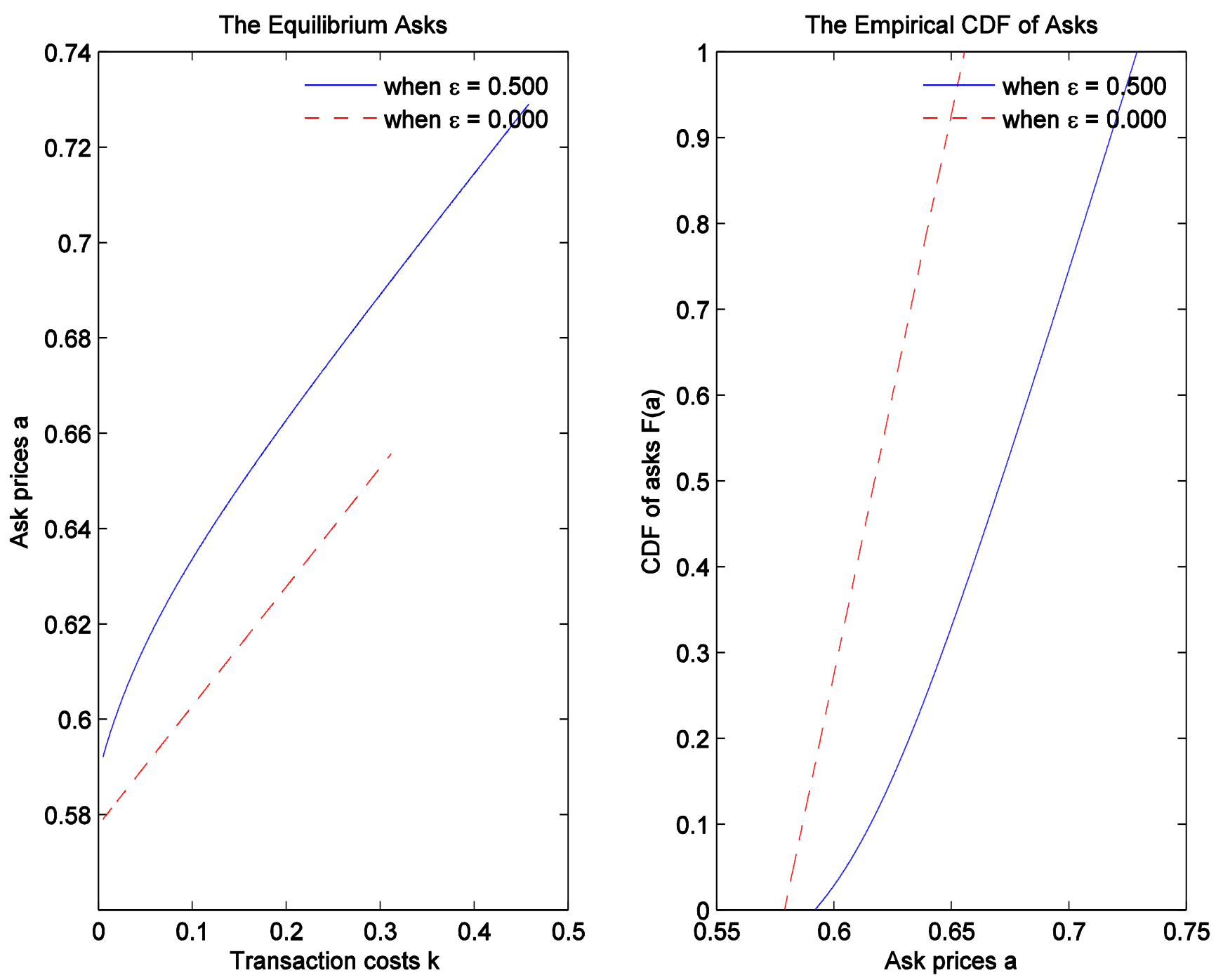
Figure 4: The comparison of traders' reservation values between a less transparent OTC market $(\epsilon=0.5)$ and a completely transparent OTC market $(\epsilon=0)$. Solid lines show the reservation values when the OTC market is less transparent, and dashed lines show the reservation values when the OTC market is completely transparent. The left panel plots buyers' reservation buying prices, and the right panel plots sellers' reservation selling prices.
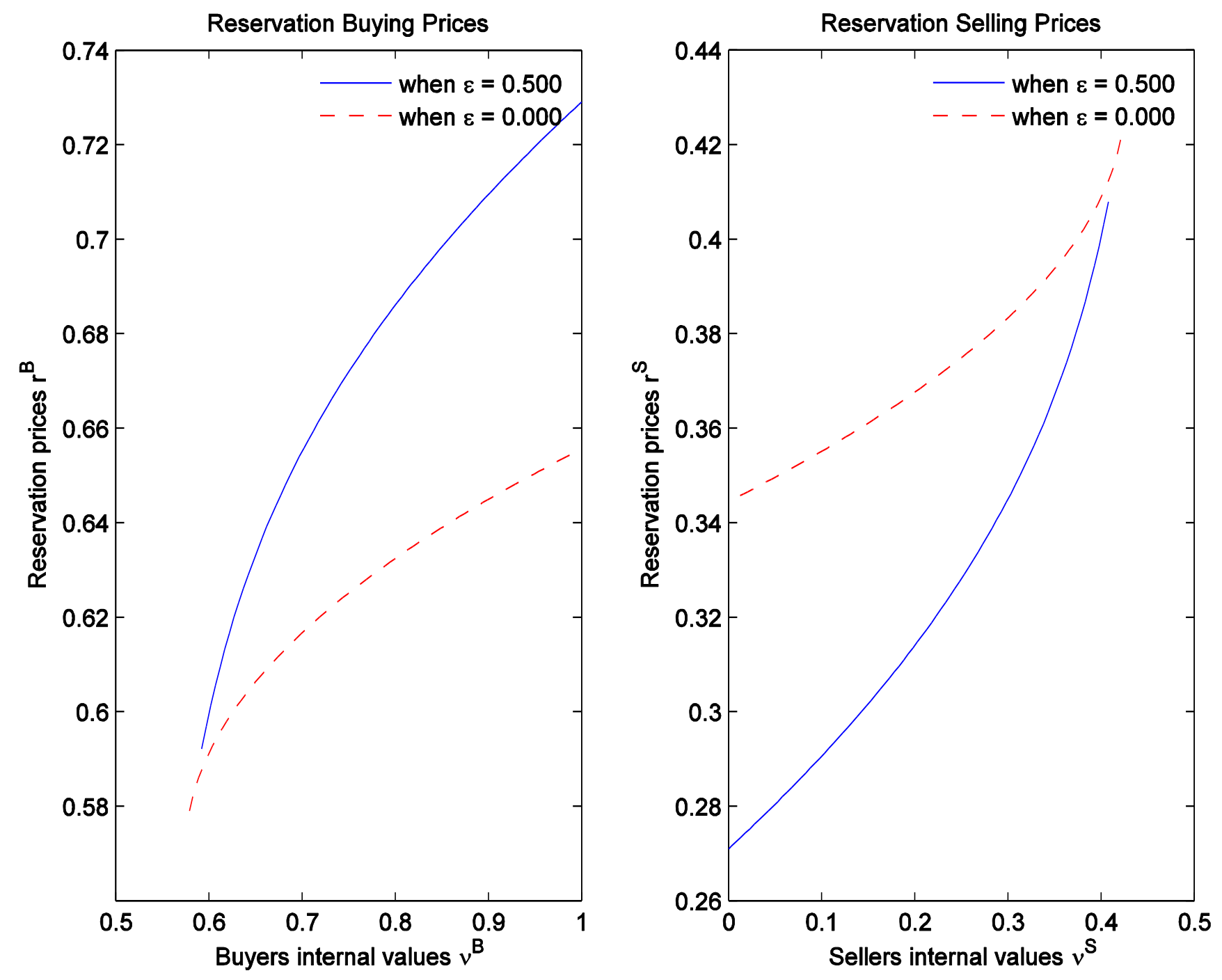
Figure 5: Comparative statics of the welfare in the equilibrium of Proposition 1 with respect to $\epsilon$. Parameters are the same as in Figure 1. The left panel plots traders' surplus, and the right panel plots dealers' total profits.
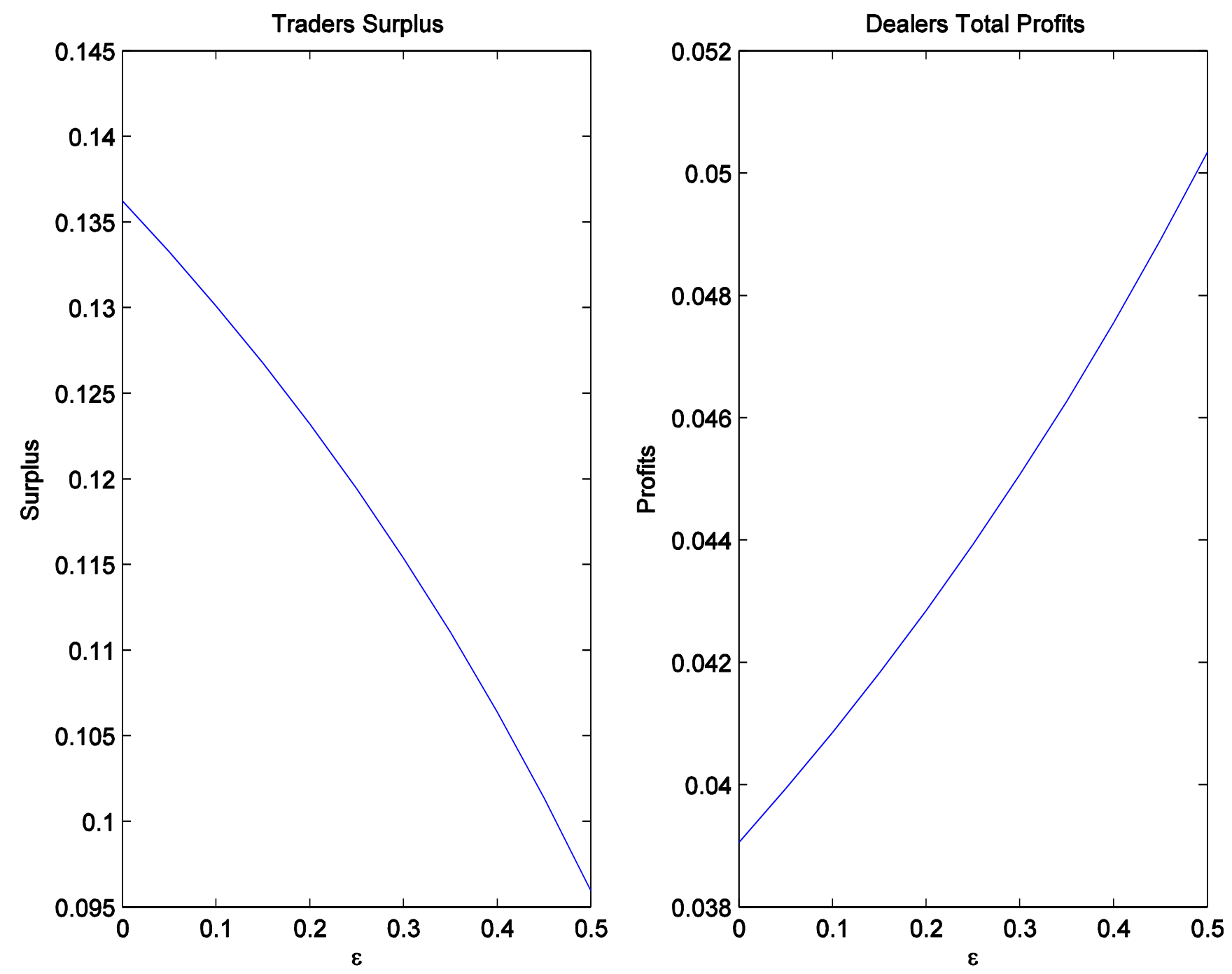